ANDRÉ NATHAN COSTA

\title{
Análise clínica, tomográfica, funcional e da qualidade de vida em pacientes com paracoccidioidomicose crônica inativa
}

Tese apresentada à Faculdade de Medicina da Universidade de São Paulo para obtenção do título de Doutor em Ciências

Programa Pneumologia

Orientador: Prof. Dr. Carlos Roberto Ribeiro de Carvalho

São Paulo 
Dados Internacionais de Catalogação na Publicação (CIP)

Preparada pela Biblioteca da

Faculdade de Medicina da Universidade de São Paulo

Creprodução autorizada pelo autor

Costa, André Nathan

Análise clínica, tomográfica, funcional e da qualidade de vida em pacientes com paracoccidiodomicose crônica inativa / André Nathan Costa. -- São Paulo, 2012.

Tese (doutorado)--Faculdade de Medicina da Universidade de São Paulo. Programa de Pneumologia.

Orientador: Carlos Roberto Ribeiro de Carvalho.

Descritores: 1.Paracoccidiodomicose 2.Espirometria 3.Tomografia computadorizada por raios X 4.Qualidade de vida 5.Tolerância ao exercício

USP/FM/DBD-126/12 
Dedicatória 
À Susi, que com seu sorriso incondicional ilumina cada momento da minha vida. 
Agradecimentos 
Ao orientador, amigo e exemplo, Prof.Dr. Carlos Carvalho. Ídolo e modelo de qualquer aluno que sentou nos bancos da FMUSP ou nas cadeiras da Pneumologia. Obrigado por me ensinar a preocupação incansável com os pacientes, e a igual determinação e entusiasmo pelo ensino.

Ao $\mathrm{Dr}$ Ronaldo Kairalla, com seu extraordinário conhecimento e senso crítico, por compartilhar comigo seu dom de pneumologista. Pela oportunidade de trabalharmos juntos no HC e Hospital Sírio Libanês, pela chance de dividirmos pacientes e preocupações, mas também conquistas e alegrias.

Ao prof. Carlos Corbett, amigo e tutor, companheiro de jornadas amazônicas inesquecíveis e de aventuras etílicas incomparáveis. A ele devo o gosto pelo ambiente acadêmico e os primeiros passos em direção à ciência, além da importância da consciência social do exercício da medicina.

Aos professores Mário Terra e Rogério de Souza pelo trabalho realizado junto à pós -graduação da Pneumologia.

Aos colegas da Pneumologia, aos companheiros do Grupo de Interstício, e em especial aos amigos Bruno e Olívia por esses anos de profícuo trabalho conjunto. Ao Dr. João Marcos e Dr. Andre Albuquerque e a todo grupo da Função Pulmonar (Fabiane, Milena, Vanessa), sem os quais esse trabalho seria impossível.

À Dra. Tereza, que além de ensinar a cuidar dos pacientes me ajudou curando minha apneia do sono.

À equipe do Ambulatório de Micoses, profa Shikanai, Adriana Kono e Gil Benard, que me acolheram tão bem e deram substrato para realização desse projeto. 
À família da UTI AC Camargo, grupo de profissionais de qualidade técnica inquestionável, e de caráter e honestidade singulares.

Aos colegas de trabalho do Sírio Libanês, Andre Apanavicius e Rafael Musolino, companheiros da equipe de Pneumologia, sempre ao lado nos momentos mais indispensáveis e sempre prontos pra ajudar quando preciso.

Aos colegas Caio Julio, Lucio Santos e Pedro Medeiros, com quem aprendi muito sobre a medicina e mais ainda sobre a vida.

Aos amigos de panela, com quem dividi e ainda divido alguns dos momentos mais fantásticos da minha vida, e que me acompanharam na formação de médico e pessoa. Digo, Tio, Carol, Mari, Maria Carol, Lucky, Ivan. Orgulho e saudade do tempo que repartimos juntos nossos dias e noites, aprendizados e angústias, plantões e acampamentos.

Aos sócios dos bares, na verdade muito mais amigos que sócios, que permitiram que eu fizesse uma das coisas mais divertidas que se possa imaginar: ser dono de um bar. Ao Jani, amigo e companheiro fiel nas corridas e bicicletas, copos, mesas de bar e conversas fiadas.

Aos amigos de São José, que incrivelmente estão juntos até hoje, apesar da distância do ginásio. Masca, Analu, Sola e Déia, amo vocês.

Aos meus pais, Ana Maria e Armando, que me deram os bens mais importantes na formação de uma pessoa, o amor e a educação.

Minha mãe, exemplo de amor incondicional e colo seguro em qualquer momento da minha vida, se virando em muitas pra que nunca me faltasse esteio pra superar as adversidades.

Meu pai, que me ensinou que ser íntegro e autêntico deve ser característica irrevogável no caráter de um homem. 


\begin{abstract}
À Déia, irmã sempre presente, melhor amiga, exemplo de força e determinação. Eu não seria metade do que sou hoje sem sua presença constante do meu lado. Obrigado.
\end{abstract}

Aos meus sogros, Evaristo e Rosa, sempre prontos pra ajudar, que me acolheram de braços e sorrisos abertos em sua família.

À Susi, companheira incondicional, fonte de alegria e entusiasmo, dona de uma bondade e felicidade contagiantes, que me ensinou que ser feliz é muito mais fácil do que eu imaginava. Te amo.

À Maria, pois depois de sua vinda descobri um novo significado para o amor. Por ela me esforço diariamente para ser uma pessoa melhor.

E ao pequeno Francisco, ainda por vir, mas já me enchendo de orgulho. 


\section{NORMALIZAÇÃO ADOTADA}

Esta dissertação ou tese está de acordo com as seguintes normas em vigor no momento desta publicação:

Referências: adaptado de International Committee of Medical Journals Editors (Vancouver).

Universidade de São Paulo. Faculdade de Medicina. Divisão de Biblioteca e Documentação. Guia de apresentação de dissertações, teses e monografias. Elaborado por Anneliese Carneiro da Cunha, Maria Julia de A. L. Freddi, Maria F. Crestana, Marinalva de Souza Aragão, Suely Campos Cardoso, Valéria Vilhena. 3a ed. São Paulo: Divisão de Biblioteca e Documentação; 2011.

Abreviaturas dos títulos dos periódicos de acordo com List of Journals Indexed in Index Medicus. 


\section{SUMÁRIO}

Lista de abreviaturas e siglas

Lista de símbolos

Lista de tabelas

Lista de figuras

Resumo

Summary

1. INTRODUÇÃO

1.1 Histórico 2

1.2 O fungo 3

1.3 Epidemiologia 4

1.4 Ecologia 6

1.5 Imunopatogenia 8

1.5.1 Imunopatogenia das alterações fibróticas pulmonares 9

$\begin{array}{ll}1.6 \text { Diagnóstico } & 10\end{array}$

1.7 Formas clínicas $\quad 12$

1.7.1 Paracoccidioidomicose infecção 12

1.7.2 Paracoccidioidomicose forma juvenil 12

1.7.3 Paracoccidioidomicose forma crônica 13

1.8 As lesões pulmonares na forma crônica da paracoccidioidomicose $\begin{array}{ll}\text { e suas repercussões tardias } & 14\end{array}$

$\begin{array}{lr}\text { 2. OBJETIVOS } & 18\end{array}$

3. MÉTODOS 20

$\begin{array}{ll}3.1 \text { Seleção dos pacientes } & 21\end{array}$

3.1.1 Critérios de Inclusão 21

3.1.2 Critérios de Exclusão 22

3.2 Delineamento do estudo 22

$\begin{array}{ll}3.3 \text { Avaliações realizadas } & 23\end{array}$ 
3.3.1 Tomografia de tórax alta resolução 23

3.3.2 Prova de função pulmonar 24

3.3.3 Teste de caminhada de seis minutos 24

3.3.4 Teste de exercício cardiopulmonar 25

3.3.5 Questionários de dispnéia e qualidade de vida relacionada à saúde 26

$\begin{array}{ll}3.4 \text { Análise Estatística } & 27\end{array}$

4. RESULTADOS 28

4.1 Casuística e características clínico-demográficas 29

4.2 Tomografia de tórax alta resolução 32

4.2.1 Padrões das Tomografias de tórax em alta resolução 37

4.3 Avaliações funcionais 40

4.3.1 Prova de função pulmonar $\quad 40$

4.3.2 Teste de caminhada de seis minutos 44

4.3.3 Teste de exercício cardiopulmonar 44

4.4 Avaliação da qualidade de vida e do índice de dispneia 47

4.5 Correlações das variáveis avaliadas com a sorologia inicial 49

4.6 Comparação entre dois grupos A e B divididos quanto a gravidade medida pela dessaturação ao TC6M 49

5. DISCUSSÃO

$\begin{array}{ll}\text { 6. CONCLUSÃO } & 69\end{array}$

7. REFERÊNCIAS BIBLIOGRÁFICAS

8. APÊNDICES 79 


\section{LISTA DE ABREVIATURAS E SIGLAS}

$\begin{array}{ll}\text { ABNT } & \text { Associação Brasileira de Normas Técnicas } \\ \text { AT } & \text { limiar anaeróbico } \\ \text { ATS } & \text { American Thoracic Society } \\ \text { BD } & \text { broncodilatador } \\ \text { BPM } & \text { batimentos por minuto } \\ \text { Btps } & \text { Body Temperature Pressure Saturated } \\ \text { CAPPesq } & \text { Comissão de Ética para a Análise de Projetos de } \\ \text { CI } & \text { Pesquisa } \\ \text { CIE } & \text { capacidade inspiratória } \\ \text { CO } & \text { contraimunoeletroforese } \\ \text { CPT } & \text { dióxido de carbono } \\ \text { CVF } & \text { capacidade pulmonar total } \\ \text { DLCO } & \text { capacidade vital forçada } \\ \text { DP } & \text { difusão de monóxido de carbono } \\ \text { DPOC } & \text { desvio padrão } \\ \text { ed. } & \text { doença pulmonar obstrutiva crônica } \\ \text { ELISA } & \text { edição } \\ \text { et al } & \text { ensaio imunoenzimático } \\ \text { FMUSP } & \text { e outros } \\ \text { FR } & \text { Faculdade de Medicina da Universidade de São Paulo } \\ \text { GM-CSF } & \text { freqüência respiratória } \\ \text { IB } & \text { fator de estimulação de colônias de granulócitos e } \\ \text { ID } & \text { macrófagos } \\ \text { IFI } & \text { imunoblot } \\ \text { IL } & \text { imunodifusão dupla } \\ \text { INF- Y } & \text { imunofluorescência indireta } \\ \text { IQ } & \text { interleucina } \\ & \text { interferon gama } \\ \text { interquartil }\end{array}$


MRC

$\mathrm{O}_{2}$

$\mathrm{Pb}$

Pbmicose

PCM

PCR

PFP

RER

$\mathrm{SpO}_{2}$

TC6M

TCAR

TECP

TGF- $\beta$

TNF- $\alpha$

USP

$\mathrm{VCO}_{2}$

$\mathrm{Vd} / \mathrm{Vt}$

VE

$\mathrm{VE} / \mathrm{VCO}_{2}$

$\mathrm{VE} / \mathrm{VO}_{2}$

$\mathrm{VEF}_{1}$

$\mathrm{VO}_{2}$

$\mathrm{VO}_{2} \max$

$\mathrm{VR}$

VVM medical research council

oxigênio

Paracoccidioides brasiliensis

Paracoccidioidomicose

Paracoccidioidomicose

reação em cadeia de polimerase

prova de função pulmonar

taxa de troca gasosa

saturação periférica de oxigênio

teste de caminhada de seis minutos

tomografia computadorizada de alta resolução

teste de exercício cardiopulmonar

fator de transformação do crescimento beta

fator de necrose tumoral alfa

Universidade de São Paulo

produção de dióxido de carbono $\left(\mathrm{VCO}_{2}\right)$

relação espaço morto/volume corrente

ventilação minuto (VE, L/min)

equivalente ventilatório para o $\mathrm{CO}_{2}$

equivalente ventilatório para $\circ \mathrm{O}_{2}$

volume expirado ao final do primeiro segundo

consumo de oxigênio

consumo máximo de oxigênio

volume residual

ventilação voluntária máxima 


\section{LISTA DE SÍMBOLOS}

$\begin{array}{ll}\mathrm{KDa} & \text { quilodalton } \\ \mathrm{L} & \text { litros } \\ \mathrm{L} & \text { litros } \\ \mathrm{L} / \mathrm{min} & \text { litros por minuto } \\ \mathrm{L} / \mathrm{s} & \text { litros por segundo } \\ \mathrm{m} & \text { metros } \\ \mathrm{Mb} & \text { megabase } \\ \mathrm{min} & \text { minutos } \\ \mathrm{mL} & \text { mililitros } \\ \mathrm{mL} / \mathrm{kg} / \mathrm{min} & \text { mililitros por quilo por minuto } \\ \mathrm{mL} / \mathrm{mmHg} & \text { mililitro por milímetro de mercúrio } \\ \mathrm{mmHg} & \text { milímetros de mercúrio } \\ \mathrm{S} & \text { segundos } \\ \mathrm{UI} & \text { unidade internacional } \\ \mathrm{W} & \text { watts } \\ \mu \mathrm{m} & \text { micrometro } \\ < & \text { menor que } \\ > & \text { maior que } \\ \leq & \text { menor ou igual que } \\ \geq & \text { maior ou igual que } \\ \pm & \text { mais ou menos }\end{array}$




\section{LISTA DE TABELAS}

Tabela 1 - Dados clínico - demográficos dos 50 pacientes avaliados

Tabela 2 - Resultados da tomografia de tórax de alta resolução

Tabela 3 - Distribuição dos achados principais da tomografia de tórax

Tabela 4 - Quantificação do enfisema quanto ao grau de extensão

Tabela 5 - Resultados das análises dos volumes, fluxos e capacidades pulmonares, difusão e ventilação voluntária máxima dos pacientes avaliados

Tabela 6 - Resultados dos volumes e fluxos pulmonares, após uso de broncodilatador (BD)

Tabela 7 - Resultados do teste de caminhada de seis minutos

Tabela 8 - Resultados do teste de exercício cardiopulmonar I

Tabela 9 - Resultados do teste de exercício cardiopulmonar II

Tabela 10 - Pontuação no Questionário do Hospital Saint George na Doença Respiratória

Tabela 11 - Resultados do Questionário do Medical Research Council

Tabela 12 - Dados clínico - demográficos dos dois grupos (A x B)

Tabela 13 - Resultados das comparações dos volumes, fluxos e capacidades pulmonares e ventilação voluntária máxima nos dois grupos de pacientes

Tabela 14 - Comparação do teste de caminhada de seis minutos entre os dois grupos $\mathrm{A}$ e $\mathrm{B}$ 
Tabela 15 - Comparação das variáveis ventilatórias entre os dois grupos A e B

Tabela 16 - Pontuação no Questionário do Hospital Saint George na Doença Respiratória nos grupos A e B 


\section{LISTA DE FIGURAS}

Figura 1: Dados relacionados às medicações antifúngicas utilizadas pelos 50 pacientes

Figura 2: TCAR ao nível dos lobos superiores mostrando espessamento septal e reticulado de distribuição periférica

Figura 3: TCAR ao nível dos lobos superiores evidenciando distorção da arquitetura

Figura 4: TCAR ao nível dos lobos inferiores demonstrando bandas parenquimatosas

Figura 5: TCAR ao nível dos lobos inferiores exemplificando nódulo em lobo inferior esquerdo, e foco de vidro fosco no lobo inferior direito

Figura 6: TCAR ao nível dos lobos superiores evidenciando enfisema centrolobular e parasseptal

Figura 7: TCAR ao nível dos lobos inferiores com áreas de espessamento do interstício peribroncovascular

Figura 8: TCAR em expiração com padrão em mosaico, evidenciando áreas de aprisionamento aéreo em lobos inferiores

Figura 9: Valores de $\mathrm{VO}_{2}(\mathrm{~mL} / \mathrm{kg} / \mathrm{min})$ mostrando relação positiva com a distância, em metros, do teste de caminhada de seis minuto

Figura 10 - Holter de oximetria de paciente com intensa dessaturação no TC6M, ilustrada através do gráfico de $\mathrm{SpO}_{2}$ pelo tempo do teste 
Figura 11 - Comparação entre o número de alterações tomográficas nos grupos A e B

Figura 12 - Comparação entre a incidência de alterações fibróticas nos grupos A e B

Figura 13 - Comparação entre o grau de enfisema nos grupos A e B 


\section{RESUMO}

Costa AN. Análise clínica, tomográfica, funcional e da qualidade de vida em pacientes com Paracoccidioidomicose crônica inativa [tese]. São Paulo: Faculdade de Medicina, Universidade de São Paulo; 2012.

INTRODUÇÃO: Micose sistêmica mais importante da América do Sul e do Brasil, a Paracoccidioidomicose acomete difusamente os pulmões no seu principal modo de apresentação, a forma crônica. Os pacientes podem apresentar anormalidades respiratórias com repercussão clínica e na qualidade de vida relacionada à saúde mesmo após tratamento antifúngico adequado. Não há, todavia, estudos que avaliem as alterações pulmonares radiológicas e funcionais e sua real incidência e repercussão clínica e na qualidade de vida desses pacientes após o tratamento. MÉTODOS: Análise transversal de 50 pacientes através de tomografia computadorizada de tórax, prova de função pulmonar completa, teste cardiopulmonar de esforço, teste de caminhada de seis minutos (TC6M) e questionário de qualidade de vida relacionada à saúde e de índice de dispneia. Todos tiveram diagnóstico da forma crônica da paracoccidioidomicose e foram avaliados quando atingiram critérios de inatividade de doença. RESULTADOS: Os pacientes apresentaram anormalidades tomográficas em $98 \%$ dos casos, sendo distorção da arquitetura (90\%), reticulado (88\%), enfisema centrolobular e parasseptal $(84 \%)$ e bandas parenquimatosas $(74 \%)$ as mais frequentes. Os achados foram principalmente difusos, e foi predominante a combinação das localizações central e periférica $(80 \%)$. Do ponto de vista funcional, apresentaram, em média, distúrbio obstrutivo leve sem resposta ao broncodilatador, com redução leve da difusão do $\mathrm{CO}$. Ao teste de esforço cardiopulmonar, atingiram média de $\mathrm{VO}_{2}$ máx dentro da normalidade, e à caminhada de seis minutos atingiram distância média dentro da normalidade. O questionário de qualidade de vida relacionado à saúde mostrou um impacto baixo na qualidade de vida, e o índice de dispneia 
mostrou alteração leve (MRC 1). Quando divididos em dois grupos em relação à dessaturação no TC6M, o grupo mais grave apresentou valor de CIE inicial mais alto e mais enfisema na TCAR, porém não houve diferença na exposição tabágica, no número de alterações tomográficas cicatriciais encontradas, na capacidade aeróbica medida pelo TCPE e TC6M e tampouco no questionário de qualidade de vida relacionada à saúde ou índice de dispneia. CONCLUSÃO: $\mathrm{Na}$ forma crônica da paracoccidioidomicose, após tratamento antifúngico e atingidos critérios de inatividade de doença, os pacientes apresentam anormalidades tomográficas persistentes e disseminadas, porém sem determinar um comprometimento grave na função pulmonar, capacidade aeróbica ou qualidade de vida relacionada à saúde. Todavia, uma parcela da população tem acometimento funcional mais grave, com maior alteração da troca gasosa levando a maior dessaturação ao exercício. Ao ser estudado distintamente, esse grupo de indivíduos não se diferencia do restante em termos de exposição tabágica, capacidade aeróbica, impacto na qualidade de vida relacionada à saúde e índice de dispneia ou número de alterações radiológicas intersticiais cicatriciais encontradas na tomografia computadorizada de tórax, porém apresenta sorologia inicial (CIE) mais alta e enfisema mais proeminente na TCAR.

Descritores: Paracoccidioidomicose, espirometria, tomografia computadorizada por raios $\mathrm{x}$, qualidade de vida, tolerância ao exercício 


\begin{abstract}
Costa AN. Clinical, tomographic, functional and health related quality of life evaluation in inactive chronic Paracoccidioidomycosis [thesis].
\end{abstract}

BACKGROUND: Paracoccidioidomycosis (PCM), the most important systemic mycosis in Latin America and Brazil, can diffusely affect the lungs in its mains form of presentation, the chronic form. Even after adequate antifungal therapy, the patients may present residual respiratory abnormalities with potential clinical, functional and health-related quality of life impairment, due to fungus-induced lung fibrosis. METHODS: Crosssectional analysis of 50 consecutive inactive chronic Paracoccidioidomycosis patients, through high resolution computed tomography (HRCT) reviewed by a chest radiologist and a pulmonologist, pulmonary function tests with diffusion capacity, ergoespirometry, six minute walk test (6MWT) and healthrelated quality of life questionnaire. All patients had achieved inactivity criteria when evaluation was performed. RESULTS: Radiological abnormalities were present in $98 \%$ of the cases, and the most frequent were architectural distortion (90\%), reticulate and septum thickening (88\%), centrolobular and parasseptal emphysema (84\%) and parenchymal bands (74\%). The findings were mainly diffuse, and predominantly with a combination of central and peripheral locations (80\%). From the functional standpoint the patients presented, in average, a mild obstructive disorder without bronchodilator response, associated to a mild reduction in diffusion capacity. The ergoespirometry demonstrated a mean $\mathrm{VO}_{2}$ máx in the range of normality, and the patients achieved a mean normal distance in the 6MWT. The SaintGeorge Respiratory Questionnaire evaluation showed a low total impairment in health-related quality of life and the MRC questionnaire a low dyspnae index. When split in two groups in terms of exercise desaturation in the $6 \mathrm{MWT}$, the more severely impaired group presented a higher initial serology (CIE) and more severe emphysema graded by HRCT, but there was no difference between the two groups in regards to interstitial fibrotic 
tomographic abnormalities, tobacco exposure, exercise capacity measured by ergoespirometry and 6MWT, nor in the health related quality of life and dyspnae index. CONCLUSIONS: In the chronic form of Paracoccidioidomycosis, after antifungal treatment, the patients show persistent and disseminated radiological abnormalities, but these findings appear to determine a short impairment in pulmonary function and low impact in aerobic capacity and health-related quality of life. However, in a minor subset of individuals the functional impairment can be severe. When this group is distinctly studied, the individuals present no difference in tobacco exposure, interstitial fibrotic radiological findings, exercise capacity nor health related quality of life and dyspnae index when compared to less severely afflicted patients, but do so in terms of higher initial serology (CIE) and severity of emphysema quantification by HRCT.

Keywords: Paracoccidioidomycosis, spirometry, $x$-ray computed tomography, quality of life, exercise tolerance 


\section{INTRODUÇÃO}




\section{INTRODUÇÃO}

\subsection{Histórico}

O ano era 1908, e naquele $1^{\circ}$ de abril o pesquisador Adolpho Lutz, do Instituto Bacteriológico de São Paulo, publicava a primeira descrição do que ele chamou de "mycose pseudococcidica localizada na bocca e observada no Brazil" 1, 2. No número 22 do periódico Brazil-Médico, Lutz descreveu a paracoccidioidomicose como uma doença caracterizada por lesões muito graves, com úlceras que destruíam a mucosa da gengiva e o véu palatino associadas à dolorosa repercussão ganglionar, qualificando-a como micose pseudococcídica após identificar seu agente causal, um fungo de natureza dimórfica distinta do Coccidioides immitis ${ }^{3}$. Quatro anos depois, Alfonso Splendore classificou o agente etiológico da paracoccidioidomicose dentro do gênero Zymonema, propondo a denominação de Zymonema brasiliensis. Já na década de 30, nova classificação foi proposta por Floriano Paulo de Almeida ao diferenciar o granuloma coccidióico nos Estados Unidos e no Brasil 3,4, 5. Posteriormente, com a observação de casos da doença em outros países da América do Sul, propôs-se a nomenclatura de blastomicose sul-americana, doença de Lutz, e finalmente doença de Lutz-SplendoreAlmeida, pois Splendore foi o primeiro a cultivar o patógeno e Almeida o autor do primeiro estudo abrangente sobre a doença ${ }^{6}$. A oficialização do termo Paracoccidioidomicose (PCM) foi somente estabelecida em 1971, em Medellín, Colômbia, durante reunião de micologistas de todo o continente americano, sendo mundialmente aceita desde então ${ }^{7}$.

Desde a primeira descrição por Lutz já se passaram pouco mais de cem anos, e, graças ao trabalho de outros incansáveis investigadores brasileiros e sul-americanos, hoje se distingue o fungo Paracoccidioides brasiliensis $(\mathrm{Pb})$ como entidade taxonômica reconhecida e responsável pela gênese da doença Paracoccidioidomicose ${ }^{2}$. Os progressos na caracterização do fungo levaram ao sequenciamento do seu genoma, à avaliação dos fatores moleculares que levam à transição da forma de hifa à 
de levedura, à determinação dos fatores de virulência e da importância das glicoproteínas como a gp43 na patogênese e mediação da resposta imune do hospedeiro ${ }^{8}$. Contudo, ainda hoje há muitas lacunas no conhecimento desse microorganismo, seja do ponto de vista de sua taxonomia, reprodução e interação com o hospedeiro, seja do ponto de vista das repercussões clínicas enfrentadas pelos indivíduos infectados. São essas dúvidas que ainda levam inúmeros cientistas a tentar diariamente completar o quebracabeça desse instigante microorganismo.

\subsection{Fungo}

O fungo Paracoccidioides brasiliensis taxonomicamente encontra-se atualmente no Reino Fungi, Filo Ascomycota, Classe Pleomycetes, Ordem Onigenales, Família Onygenaceae, Gênero Paracoccidioides e Espécie brasiliensis ${ }^{9}$. Mais recentemente, Matute et al propuseram, através de estudos genotípicos, três espécies crípticas diferentes: S1, S2 e S3, que estariam diversamente distribuídas pela Argentina, Brasil, Colômbia, Peru e Venezuela ${ }^{10}$. Além disso, variações genéticas descritas na codificação de regiões do $P$. brasiliensis indicam que pode haver, ainda, mais espécies filogenéticas que as três atualmente descritas ${ }^{9}{ }^{91}$. Do ponto de vista genético, quatro a cinco cromossomos que variam de 2 a $10 \mathrm{Mb}$ de tamanho foram identificados, com o genoma estimado em 23 a $30 \mathrm{Mb}$ indicando a presença de 10 a 15 mil genes ${ }^{12}$. O tipo de multiplicação é assexuado, porém foi sugerida a presença de genes relativos à reprodução sexuada e também à recombinação gênica intraespécie ${ }^{13}$.

Morfologicamente, $P$. brasiliensis é um fungo termal dimórfico que cresce na forma de micélio em baixas temperaturas $\left(4^{\circ}\right.$ a $\left.26^{\circ} \mathrm{C}\right)$ e de leveduras em tecidos e culturas a $37^{\circ} \mathrm{C}^{14}$.

Quando incubado entre 18 a $25^{\circ} \mathrm{C}$, o microorganismo na forma de micélio cresce lentamente em vinte a trinta dias, formando colônias brancas pequenas e irregulares, fortemente aderentes ao meio Agar, podendo apresentar coloração amarronzada pela produção de um pigmento 
semelhante à melanina. Microscopicamente, visualizam-se hifas finas e septadas, produtoras de clamidoconídeas e clamidósporos que são conhecidas como as formas propagantes inalatórias do fungo ${ }^{14-16}$. Já quando cultivado a $37^{\circ} \mathrm{C}$, em cerca de dez dias o P. brasiliensis forma colônias cerebriformes macias e de cor creme ${ }^{14}$, que por isso já foram chamadas por Lutz de "pelos de ratinhos brancos" ${ }^{4}$. Em tecidos e culturas a $37^{\circ} \mathrm{C}$ o fungo se apresenta como células leveduriformes ovaladas, em geral multinucleadas, com paredes espessadas e birrefringentes, de tamanho variável (6 a $40 \mu \mathrm{m}$ ), algumas com aparência característica de "roda de leme de navio" pelos multibrotamentos da célula mãe rodeada de blastoconídeos de 2 a $10 \mu \mathrm{m}$ de tamanho ${ }^{14,}{ }^{17}$. Essa fase, também conhecida como parasitária, permite o diagnóstico da doença fúngica pela simples observação dessas estruturas em análise direta de tecidos ${ }^{17}$.

\subsection{Epidemiologia}

A PCM é limitada geograficamente à América Latina, restringindo-se a área entre o México e a Argentina, mais precisamente entre latitude $23^{\circ} \mathrm{N} \mathrm{e}$ $34,5^{\circ} \mathrm{S}$, regiões onde se registram os casos autóctones ${ }^{18,17,19,20}$. É mais frequente na América do Sul e o Brasil é responsável por $80 \%$ dos casos mundiais, sendo assim nosso país aquele que lidera a incidência dessa micose no mundo, seguido de Colômbia, Venezuela, Argentina e Equador ${ }^{21,20}$. Infelizmente, pela PCM não ser doença de notificação compulsória em nosso país e pela falta de estudos epidemiológicos no Brasil, não há dados precisos sobre sua incidência ${ }^{19,22}$. Também serve como fator dificultador das informações epidemiológicas o fato de a PCM ser doença que afeta primariamente população desprivilegiada economicamente, como trabalhadores rurais e moradores de regiões com pouco acesso aos serviços de saúde ${ }^{19,20,23}$.

Acredita-se que a incidência anual alcance 1 a 4 casos novos / 100 mil habitantes/ano, dependendo da região estudada ${ }^{23}$. Nessas regiões, até dois terços da população pode ter tido contato prévio com o fungo durante a 
vida, o que significa, no Brasil, que até $10 \%$ da população pode estar infectada pelo fungo ${ }^{24,25}$. Coutinho e colaboradores mostraram a dimensão do problema ao descrever a PCM como a oitava causa de morte entre as doenças infecto-parasitárias no Brasil, sendo ela a principal causa de morte entre as micoses sistêmicas em território nacional, atingindo mortalidade de 0,14 por 100.000 habitantes ${ }^{19,22,26}$, e com o número anual de mortes por paracoccidioidomicose no Brasil alcançando a média de 168 durante o período de 1996 a $2006{ }^{27}$. Em estudo recente, Prado e associados mostraram ser a PCM a principal causa de morte entre as micoses sistêmicas em solo brasileiro, representando $51,2 \%$ das mortes por esse tipo de enfermidade ${ }^{27}$. Na maior série de casos ja publicada, BellissimoRodrigues et al analisaram 1.000 pacientes brasileiros e indicou que no período de 1980 a 1999, a taxa de incidência para o distrito de Ribeirão Preto no Estado de São Paulo teve média de 2,70 casos por 100.000 habitantes. Entretanto, apesar desses dados, essa endemia é marcada pela baixa visibilidade e falta de recursos a ela destinada, levando à desnecessariamente elevada morbi-mortalidade da já desprivilegiada população acometida.

Ainda do ponto de vista epidemiológico, a PCM é mais prevalente em adultos, que são responsáveis por $90 \%$ dos casos da doença. A infecção é prioritariamente adquirida nas duas primeiras décadas de vida, com um pico de incidência entre 10 e 20 anos de idade. A apresentação de manifestações clínicas ou a evolução para doença, entretanto, é incomum nesse grupo, ocorrendo mais frequentemente em adultos entre 30 e 50 anos, como reativação de foco endógeno latente ${ }^{5,18,23,28}$. Nos adultos ela é mais comum em homens (relação $15: 1)^{17,22}$, já na população infantil ela acomete igualmente meninos e meninas. Essa desigualdade de sexo tem sua gênese no fator estrogênico protetor, pois o fungo tem receptores para o 17- $\beta$ estradiol e esse estrógeno dificulta a conversão fúngica de conídeos a levedura, o que explica a menor incidência em mulheres adultas 29 14, 21, 30.

A associação com outras doenças granulomatosas ou neoplásicas tem sido relatada, sendo a tuberculose a mais frequente, estando presente 
como co-infeção em aproximadamente dez por cento dos casos ${ }^{23,31}$. Já a prevalência de neoplasias associadas a essa infecção fúngica é descrita como entre 3 a $6 \%$ dos casos $^{23,32}$. Os pacientes com imunossupressão, como transplantados ou portadores de linfoma, podem apresentar a reativação endógena da doença e desenvolver a forma oportunista, e aqueles com síndrome da imunodeficiência adquirida apresentam a paracoccidioidomicose oportunista em cerca de 1 a $2 \%$ dos casos em áreas endêmicas ${ }^{13}$.

Por fim, é importante ressaltar a relação de risco entre tabagismo e etilismo e a paracoccidioidomicose: o risco de desenvolver a doença é quatorze vezes maior em fumantes que em não fumantes, enquanto é 3,6 vezes maior em indivíduos que ingerem mais de $50 \mathrm{~g}$ de álcool por dia do que nos abstêmios ${ }^{33}$.

\subsection{Ecologia}

Apesar de alguns aspectos ecológicos do $P$. brasiliensis não estarem esclarecidos, evidências apontam para o solo como o habitat principal do fungo na sua forma saprofítica ${ }^{16}$. A dificuldade em se encontrar o fungo em seu nicho reside, entre outros fatores, na ausência de informações sobre surtos agudos da doença, nas frequentes migrações das populações de áreas endêmicas e no longo período de latência da doença, este último demonstrado por casos de indivíduos que desenvolvem a doença em países não endêmicos após terem vivido em regiões endêmicas no passado ${ }^{34,35}$.

Essas características típicas do paracoccidioides, que fazem com que seja difícil determinar o local exato da aquisição da infecção, levaram à proposição por Borelli do termo reservarea, que se define como local onde todos os fatores predisponentes à infecção ocorrem simultaneamente, ou seja, onde o fungo reside e o ser humano adquire a infecção primária ${ }^{36}$. Essas áreas usualmente têm temperaturas amenas $\left(17-24^{\circ} \mathrm{C}\right)$, altitude entre 1000 e 1500 m, índice pluviométrico anual moderado (900-1810 mm/ano), florestas abundantes, pequenos rios e vegetação nativa, além de inverno 
curto e verão chuvoso ${ }^{20,17}$. Já as regiões de alta endemicidade, definidas como locais onde a micose é diagnosticada ou reportada, podem ou não coincidir com a reservarea, postulando-se então a elas a definição de endemicarea ${ }^{14,17}$. Atualmente, entretanto, postula-se utilizar os termos habitat e nicho ecológico a fim de se evitar neologismos e para tornar mais claras as definições e os princípios do estudo da ecologia ${ }^{34}$.

$\mathrm{O}$ isolamento desta espécie fúngica tem sido também descrito a partir de fezes, em amostras de solo, vísceras de tatus de nove bandas (Dasypus novemcinctus), ração de cachorro contaminada com solo, trato intestinal de morcegos frutívoros e até fezes de pinguins da Antártida ${ }^{14}, 26,34,37$. Entretanto, não há dados que comprovem que esses animais, principalmente os tatus, sejam a fonte de infecção do homem pelo fungo ${ }^{17}$. Por outro lado, a demonstração de alta incidência de infecção fúngica do Dasypus novemcinctus, um mamífero silvestre que se desenvolveu na America do Sul e que vive imerso no solo, abre perspectivas para compreender a ecologia e evolução do paracoccidoides ${ }^{34,37}$. Já em termos práticos, a alta frequência de infecção do tatu de nove bandas pode ser usada para mapear possíveis áreas de incidência do fungo, pois os tatus apresentam, na obtenção de comida e reprodução, um habitat de limites bastante estreito ${ }^{34}$.

Ao longo das últimas décadas, contudo, têm sido observadas notáveis alterações na incidência, nas características demográficas da população atingida e na distribuição geográfica da PCM. Dependendo da região, a incidência se alterou, sem que se possam justificar totalmente as suas causas ${ }^{28}$. Já está claro, porém, que a distribuição da doença não se resume a fatores ecológicos atuais, mas por aspectos filogeográficos do patógeno envolvendo o passado evolucionário do fungo, sua relação com hospedeiro e ambiente e as trocas genéticas relacionadas a esses fatores ${ }^{34}$. 


\subsection{Imunopatogenia}

Está hoje amplamente aceito que a infecção pelo Paracoccidioides brasiliensis é adquirida através da inalação de propágulos fúngicos ${ }^{5,38}$, e há muito já não se considera a hipótese, antes preconizada, que a infecção humana ocorreria pela via oral, relacionada ao hábito de mascar capim ${ }^{39}$. Discute-se, entretanto, os fatores que levariam ao desenvolvimento da doença ou a manutenção do estado de portador são, da mesma forma que se descreve para a infecção por Micobacterium tuberculosis na população exposta nas áreas endêmicas ${ }^{38}$. A condição de portador ou apenas infectado é muito mais frequente que o desenvolvimento da doença ativa ${ }^{38}$.

O controle da infecção depende de resposta imune celular efetiva, geralmente associada ao padrão tipo 1 da resposta imunológica, caracterizado pela síntese de citocinas que ativam macrófagos e linfócitos $T$ CD4+ e CD8+, resultando na formação de granulomas compactos ${ }^{28}$.

Dessa forma, os macrófagos são a principal linha de defesa contra $P$. brasiliensis, através da fagocitose do fungo e inibição da sua replicação após ativação destas células por interferon y (INF-ү). Estudos verificaram que outros fagócitos, os leucócitos polimorfonucleares, também exercem efeito fungistático mediante ativação por INF- $\gamma$ e fator de estimulação de colônias de granulócitos e macrófagos $(\mathrm{GM}-\mathrm{CSF})^{7}{ }^{7},{ }^{12}, 40$. O principal antígeno de Paracoccidioides brasiliensis é uma glicoproteína extracelular de 43-KDa chamada gp $43^{41}$, para a qual indivíduos saudáveis sensibilizados estimulados produzem altos níveis de interleucina 2 (IL-2) e interleucina 10 (IL-10), além de INF- $\gamma^{42}$. Os polissacarídeos $\alpha-(1,3)$ glucana e $\beta-(1,3)$ glucana, que se relacionam com o dismorfismo fúngico, também se relacionam à virulência deste patógeno, o primeiro protegendo o fungo contra enzimas leucocitárias e macrofágicas do hospedeiro ${ }^{43}$.

Os pacientes que desenvolvem a doença produzem níveis baixos de IL-2, INF-y e fator de necrose tumoral $\alpha(\text { TNF- } \alpha)^{12}$, com modulação negativa do padrão Th-1 de citocinas e expressão de altos níveis de citocinas relacionadas à resposta Th-2 como IL-4, IL-5, IL10 e TGF- $\beta$, além de anticorpos específicos da imunoglobulina $\mathrm{E}(\lg \mathrm{E})$ e subclasses de $\lg \mathrm{G} 4$ 
associados à eosinofilia local e periférica ${ }^{17,38}$. Esse desbalanço das citocinas reduz a capacidade microbicida e de apresentação antigênica dos macrófagos ativados, levando ao desenvolvimento da paracoccidioidomicose ${ }^{12}$. Neste contexto, formas mais graves evoluem com predomínio de resposta imunológica tipo 2, na qual há maior ativação de linfócitos $\mathrm{B}$, hipergamaglobulinemia e altos títulos de anticorpos específicos, cuja magnitude, em geral, correlaciona-se positivamente com a gravidade e disseminação da doença ${ }^{28}$. Nesses pacientes, a disfunção de células $T$ pode ser documentada através na negatividade dos testes cutâneos como a paracoccidioidina. Finalmente, é também importante ressaltar a imunidade humoral como mecanismo de defesa do hospedeiro frente ao $P$. brasiliensis, havendo ativação policlonal de linfócitos $B$ e aumento dos níveis de imunoglobulinas ( $\lg A$, $\lg G$ e $\lg E$ ) que podem atuar na opsonização do fungo ${ }^{13,38}$.

\subsubsection{Patogenia das alterações fibróticas pulmonares}

Nos tecidos infectados de indivíduos imunocompetentes, a imunidade inata do indivíduo induz reação inflamatória tipicamente de padrão granulomatoso, na tentativa de restringir a proliferação e disseminação do fungo para outros órgãos do corpo ${ }^{42,44}$. Portanto a forma mais típica de reação inflamatória tecidual à presença de $P$. brasiliensis é o granuloma epitelióide, constituído por células gigantes e células epitelióides dispostas em torno das leveduras, podendo-se observar supuração e necrose de coagulação no seu interior ${ }^{14}$. Os granulomas podem ser caracterizados como compactos ou frouxos, os primeiros presentes em formas benignas e os últimos nas formas mais disseminadas ${ }^{7}, 13,45$. Estes últimos são caracteristicamente cercados de extensa fibrose com tecido cicatricial colagênico, um achado quase constante na análise anatomopatológica dessa forma da doença ${ }^{13,45}$.

Do ponto de vista morfológico, após a reativação endógena do fungo nos hilos e posterior disseminação pulmonar através da inversão do fluxo da 
linfa, as alterações da PCM assumem essa distribuição centrífuga seguindo a migração fúngica ${ }^{13,46}$. Tuder e colaboradores descreveram nos pulmões acometidos pelas lesões crônicas, além dos granulomas, fibrose densa e proliferação de fibras reticulínicas mesmo em áreas onde não se encontravam granulomas ${ }^{45}$. Na macroscopia, as lesões mostram-se predominantes nas regiões peri-hilares, com septos fibróticos se disseminando centrifugamente através do parênquima pulmonar ${ }^{13}$.

Estudos experimentais com camundongos BALB/c mostram que essa resposta fibrótica do organismo ao Paracoccidioides ocorre pelo menos 12 a 16 semanas após a inoculação nasal de formas fúngicas viáveis, com extensa resposta inflamatória frente a esses conídeos, levando não só à já descrita formação dos granulomas, mas também a uma produção excessiva e um desarranjo dos colágenos I e III no pulmão ${ }^{47,48}$. Com a evolução da infecção, mostrou-se que o colágeno frouxo e as fibras reticulínicas finas dão lugar ao colágeno denso e às fibras reticulínicas grossas, caracterizando a fibrose tecidual ${ }^{47,}{ }^{49}$. Esse processo fibrótico, entretanto, parece ser reversível em uma parcela dos animais infectados ${ }^{48}$. Do ponto de vista humoral, Franco et al mostraram o papel dos níveis elevados de TNF- $\alpha$ e do TGF- $\beta$ na indução da fibrose em camundongos infectados ${ }^{50}$; e, mais recentemente, Naranjo e associados propuseram um possível papel protetor da pentoxifilina, um conhecido antagonista da produção de receptores de TNF- $\alpha$, através de seus efeitos antifibróticos inibindo a proliferação fibroblástica e a síntese de glicosaminoglicanas, fibronectina e colágeno que estão exacerbadas na infecção pulmonar por Paracoccidioides ${ }^{49}$. Essa droga teria papel ao diminuir a incidência da mais temida consequência da paracoccidioidomicose pulmonar, que é o desenvolvimento da fibrose e suas repercussões clínicas e funcionais nos indivíduos infectados, historicamente descritas como extensas e incapacitantes ${ }^{14,49}$.

\subsection{Diagnóstico}

O diagnóstico laboratorial da PCM é estabelecido pela demonstração microscópica direta do Paracoccidioides brasiliensis a partir de exame a 
fresco, biópsia ou exame histopatológico e confirmado por isolamento e identificação do fungo por cultivo, ou então, indiretamente, por técnicas sorológicas ou métodos moleculares ${ }^{7}$.

As leveduras do Paracoccidioides brasiliensis podem ser facilmente recuperadas de raspado de lesões cutâneas, secreções do trato respiratório ou punções ganglionares, com a imediata visualização ao microscópio ótico das formas fúngicas características após a clarificação dos materiais com solução de $\mathrm{KOH}^{13}$. No caso do lavado broncoalveolar, além da pesquisa direta, é possível identificar um infiltrado linfocítico com aumento dos linfócitos T CD8+ ${ }^{51,52}$.

As provas sorológicas específicas não só têm valor no diagnóstico como também permitem avaliação da resposta do hospedeiro ao tratamento. Atualmente, são disponíveis os métodos de imunodifusão dupla (ID), contraimunoeletroforese $(\mathrm{CIE})$, imunofluorescência indireta $(\mathrm{IFI})$, ensaio imunoenzimático (ELISA) e imunoblot (IB). Estes testes apresentam sensibilidade entre $85 \%$ e $100 \%$. Mais recentemente, ensaios para detecção dos antígenos gp43 e p70 têm se mostrado úteis no diagnóstico e seguimento, porém ainda não estão disponíveis para a prática clínica ${ }^{53} .0$ título de anticorpos específicos anti- $P$. brasiliensis tem, ainda, correlação com a gravidade das formas clínicas ${ }^{28}$. Nos ambulatórios do Hospital das Clínicas da FMUSP, estão disponíveis a imunodifusão dupla e a contraimunoeletroforese, esta última com resultados quantitativos.

Nos casos em que a biópsia tecidual é realizada, o quadro histopatológico é tipicamente de doença granulomatosa com células epitelióides, com o fungo no seu interior ou livre nos tecidos ${ }^{13}$. Colorações especiais como o Gomori-Groccott ou ácido periódico de Schiff podem auxiliar na pesquisa do agente etiológico ${ }^{6,7,26}$. 


\subsection{Formas clínicas}

\subsubsection{Paracoccidioidomicose infecção}

Como já foi dito, os indivíduos entram em contato com o fungo nos primeiros anos de vida, ao morar na zona rural ou em áreas endêmicas próximas de centros urbanos. A porta de entrada do $P$. brasiliensis é 0 pulmão, onde ocorre, após inalação dos conídeos, um processo inflamatório focal e auto-limitado semelhante à lesão primária de Ghon da tuberculose ${ }^{14}$, 54. Essa infecção subclínica se comprova pelos achados de lesões calcificadas residuais com o fungo no interior em pulmões de indivíduos assintomáticos, além dos inquéritos com reatividade cutânea à paracoccidioidina ou à glicoproteína $(\mathrm{gp}) 43$, provando a reação de hipersensibilidade em indivíduos saudáveis previamente sensibilizados ${ }^{55}$. Mais recentemente, Benard et al descreveram o acometimento pulmonar após infecção fúngica em indivíduo imunocompetente, resultando em extenso acometimento do sistema linfático pulmonar com repercussão clínica e radiológica agudas severas, porém com resolução espontânea dos sintomas e sem sequelas respiratórias posteriores ${ }^{54}$.

\subsubsection{Paracoccidioidomicose forma juvenil (aguda/subaguda)}

Nas situações em que a infecção pulmonar primária supera a resposta imune do hospedeiro, este desenvolve a forma aguda/subaguda da doença, também chamada de forma juvenil, que se caracteriza pelo extenso envolvimento do sistema reticuloendotelial em um continuum da infecção inicial ${ }^{17}$. Esta forma de apresentação clínica é responsável por 3 a $5 \%$ dos casos da doença, predominando em crianças e adolescentes, mas pode acometer indivíduos até os 35 anos de idade ${ }^{28}$. É a forma mais grave da doença, afeta jovens de ambos os sexos e se distingue pelo curto período 
de incubação, com evolução rápida em poucas semanas após a infecção primária, disseminando-se rapidamente por meio das vias linfáticas e envolvendo extensamente o sistema reticuloendotelial; com os indivíduos apresentando febre, perda de peso, linfadenopatia generalizada, hepatoesplenomegalia e possível disfunção medular, além de anemia, eosinofilia, hipoalbuminemia e hipergamaglobulinemia ${ }^{14,21,28,56}$. Ela se caracteriza por acentuada depressão da resposta imune celular e elevados títulos de anticorpos, e é a forma mais grave da paracoccidioidomicose, determinando pior prognóstico ${ }^{56}$. Os sintomas pulmonares e anormalidades radiológicas são raros ${ }^{54,56}$, porém é possível isolar o fungo em secreções respiratórias provando o envolvimento pulmonar, mesmo que frustro, nessa forma da doença ${ }^{54,57}$.

\subsubsection{Paracoccidioidomicose forma crônica}

A forma crônica ou forma do adulto caracteriza-se pela reativação do fungo presente em um foco quiescente dentro de um granuloma, ocorrendo mais tarde na vida do indivíduo e, na maioria dos casos, é considerada doença menos disseminada, porém com potencial maior de induzir sequelas fibróticas nos órgãos acometidos, principalmente naqueles do sistema respiratório ${ }^{17,28}$.

Essa forma clínica de reativação corresponde a mais que $90 \%$ dos casos de paracoccidioidomicose, é diagnosticada em adultos entre 30 e 60 anos e tem amplo predomínio no sexo masculino $(15: 1) 5,13,22$. Classicamente, pode-se diferenciar entre forma uni ou multi focal, acometendo os pulmões em $90 \%$ do total dos casos quando em associação com outros órgãos. Já na forma unifocal, acomete somente os pulmões em cerca de $25 \%$ dos casos ${ }^{14}$, ${ }^{17}$. Estudos com Gálio-67, entretanto, demonstram que esse órgão está comprometido, em maior ou menor grau, em praticamente todos os indivíduos na forma crônica da doença ${ }^{58}$.

Além do pulmão, virtualmente qualquer órgão do paciente pode apresentar a patologia, como membranas mucosas, linfonodos, pele, 
glândulas adrenais, ossos, fígado, baço e sistema nervoso central ${ }^{7,14}$. Por caracterizar-se como um progresso lento e de disseminação silenciosa, pode levar anos até ser diagnosticada, comumente em vários órgãos simultaneamente ${ }^{28}$. São raros os casos de formas pulmonares crônicas causando insuficiência respiratória aguda, entretanto estes casos existem e não devem ser ignorados pela gravidade e mortalidade a eles atribuídas ${ }^{59}$.

\subsection{As lesões pulmonares na forma crônica da} paracoccidioidomicose e suas repercussões tardias

Os sintomas respiratórios da PCM se instalam com sutileza, e são frequentemente subvalorizados ou atribuídos a outras causas, como o tabagismo ${ }^{60}$. A dispneia progressiva é a queixa mais frequente, tosse é observada em $57 \%$ dos casos e expectoração em $50 \%$, com hemoptóicos em cerca de $10 \%$ dos pacientes ${ }^{3,}{ }^{13}$. Sintomas como astenia e emagrecimento estão presentes em até metade dos casos, e a febre é rara ${ }^{3,}$ 5. É característica a dissociação clínico-radiológica da PCM: ausculta pulmonar revela alterações em menos da metade dos pacientes a despeito de extensas alterações radiológicas ${ }^{3,60}$. Lesões de via aéreas superiores, mucosa oral e de orofaringe são comuns e, muitas vezes, são o motivo de procura pelo serviço de saúde ${ }^{5,61}$.

As alterações encontradas no estudo radiológico pulmonar da paracoccidioidomicose não têm um padrão específico, mas comumente mostram imagens polimórficas extensas e bilaterais, predominando em campos médios e inferiores, descritas como padrão em "asa de borboleta". Cavitações são comuns ${ }^{3,5,62}$. Já a nomenclatura utilizada nas classificações radiológicas na PCM crônica é muito variável, não havendo consenso ou uma classificação universalmente aceita. As classificações variam de lesões micronodulares, infiltrativas e estriadas, passando por formas produtivas, produtivo-exsudativas e produtivo-exsudativo-escavadas, até padrões infiltrativo, nodular e fibrótico ${ }^{63}$. Valle e colaboradores descreveram, na década de 90 , os aspectos radiológicos torácicos em 139 pacientes com 
PCM atendidos no Hospital Evandro Chagas, encontrando 39,6\% de padrão infiltrativo, $16,6 \%$ padrão pneumônico, $11,5 \%$ nodular e $20 \%$ do que chamou de padrão misto (mais de um padrão concomitante). Já no ano de 2006, Trad e associados encontraram, em 132 radiografias de tórax, velamentos intersticiais reticulares em $89,3 \%$ dos casos, nodulares em $54,5 \%$, alveolares bilaterais em $45,4 \%$ e mistos em asa de borboleta em $44,7 \%{ }^{64}$.

A tomografia computadorizada de tórax de alta resolução (TCAR) tem ganhado espaço na avaliação da paracoccidioidomicose ao permitir uma avaliação mais clara do tipo de lesão, da extensão da doença e da resposta terapêutica ${ }^{5,65}$. A TCAR encontra-se alterada em até $93 \%$ dos pacientes com PCM crônica, e os principais achados, segundo Funari et al, são espessamento do septo interlobular (88\%), nódulos (83\%), bronquiectasias de tração (83\%), espessamento do interstício peribroncovascular (78\%), enfisema paracicatricial $(68 \%)$, opacidades centrolobulares $(63 \%)$, linhas intralobulares (59\%), opacidades em vidro fosco $(34 \%)$, cavitações $(17 \%)$ e consolidações $(12 \%)^{66}$. Essas alterações tendem a ser bilaterais e simétricas, frequentemente encontradas em associação umas com as outras ${ }^{65}$, e há redução na incidência de vidro fosco e consolidações nos pacientes tratados por mais de três meses ${ }^{66}$. Outro estudo tomográfico com dados brasileiros de 77 pacientes não tratados encontrou vidro fosco em $58,4 \%$ dos casos, nódulos centrolobulares em $45,5 \%$, nódulos $41,6 \%$, bandas parenquimatosas 33,8\%, enfisema cicatricial em $33,8 \%$, espessamento do septo interlobular $31,2 \%$ e distorção arquitetural em $29,9 \%$. Os achados predominaram na periferia (53\%) e regiões posteriores (88\%), envolvendo todas as zonas pulmonares ${ }^{67}$.

Mais recentemente, Marchiori e colaboradores publicaram um elegante estudo no qual se faz a correlação entre a TCAR e achados patológicos na $\mathrm{PCM}^{68}$. Nele, os autores mostram que os achados de vidro fosco correspondem à inflamação ou fibrose do septo alveolar, que áreas de consolidação e grandes nódulos irregulares se caracterizam patologicamente por exsudato inflamatório agudo no espaço alveolar, e que pequenos nódulos se correlacionam a granulomas. Finalmente, áreas de 
espessamento septal interlobular, distorção arquitetural, faveolamento e enfisema refletem áreas de fibrose ${ }^{68}$. Importante salientar que essas áreas de distorção arquitetural à tomografia se correlacionaram com fibrose caracterizada como centrolobular, envolvendo pequenas vias aéreas e pequenos vasos, com alterações enfisematosas adjacentes ${ }^{68}$.

Do ponto de vista evolutivo, a literatura ainda se pauta na radiografia simples de tórax para salientar as alterações pulmonares residuais após o tratamento. Moraes et $a l^{63}$, estudando dois grupos de pacientes com diferentes tratamentos antifúngicos, observaram regressão contínua e gradual da profusão das alterações radiográficas em $79 \%$ dos 27 pacientes avaliados, e resolução do que chamou de grandes opacidades em $90 \%$ dos casos. Não houve diferença entre o voriconazol e o itraconazol no que tange às alterações pós-tratamento ${ }^{63}$. Tobón e colaboradores, em estudo com 47 pacientes tratados com itraconazol, descreveram 57\% de alterações intersticiais ao final do tratamento, além de outras lesões residuais e bolhas em $27 \%$ e alterações radiológicas compatíveis com hipertensão pulmonar em $27,3 \%$ dos indivíduos avaliados. Sintomas como tosse, expectoração e dispneia persistiram em $38 \%$ dos pacientes ao fim do tratamento ${ }^{69}$.

Em relação aos sintomas persistentes e sequelas pulmonares, os estudos são antigos e mostram resultados conflitantes. Enquanto alguns mostram que as alterações fibróticas pulmonares alteram a função respiratória ao ponto de as atividades habituais se tornarem um fardo ${ }^{70-72}$, outros apontam o tabagismo como principal causa das incapacidades e alterações funcionais nos pacientes ${ }^{73-75}$. A alta incidência de tabagismo nas séries de casos, superior a 93\%, é fator complicador na análise dos trabalhos ${ }^{17}$. Um dado importante, entretanto, é que as evidências mostram o padrão obstrutivo como padrão espirométrico dominante na paracoccidioidomicose pulmonar $^{70}$. Afonso e associados, em 1986, estudando 35 pacientes tratados com anfotericina encontraram alterações obstrutivas em 20 indivíduos, 12 deles apresentaram espirometria simples normal e todos os 35 tiveram gradiente alvéolo-arterial alargado à gasometria arterial ${ }^{70}$. Já Lemle et al, ao comparar dezessete pacientes com 
PCM pulmonar com dezessete pacientes com DPOC, não encontraram diferenças funcionais significativas ${ }^{75}$.

Deste modo, percebe-se que a paracoccidioidomicose, apesar dos avanços no conhecimento da biologia molecular e da genética, parece ainda evoluir, após o seu tratamento, com repercussões clínicas e na qualidade de vida dos indivíduos acometidos. Não há, todavia, padronização de como se avaliar ou diagnosticar a fibrose pulmonar que se segue ao infiltrado granulomatoso da fase ativa da doença, e são poucos os estudos que avaliaram as alterações crônicas e sua real incidência e repercussão.

Estudos com pacientes tratados de PCM que avaliem o impacto das sequelas respiratórias da doença utilizando técnicas diagnósticas mais sensíveis como a tomografia computadorizada de tórax de alta resolução, fazem-se assim necessários. Além disso, análises funcionais e da capacidade aeróbica, juntamente com avaliação da qualidade de vida em relação à saúde nos pacientes com paracoccidioidomicose na forma inativa, são imprescindíveis para o conhecimento da evolução dessa afecção. Somente conhecendo a evolução e impacto cicatricial dessa patologia é que se torna possível prever o prognóstico dos pacientes e realizar o seu manejo adequado. 
2. OBJETIVOS 


\section{OBJETIVOS}

Objetivo primário: $O$ presente estudo tem como objetivo primário caracterizar o acometimento pulmonar do ponto de vista tomográfico, da capacidade funcional respiratória e da capacidade de exercício em pacientes tratados de Paracoccidioidomicose forma crônica, e avaliar o impacto na qualidade de vida relacionada à saúde das possíveis alterações respiratórias residuais.

Objetivo secundário: Encontrando-se um grupo de indivíduos com sequelas mais graves do ponto de vista de troca gasosa no exercício, o estudo tem como objetivo secundário buscar variáveis que se relacionem com esse maior impacto após o tratamento antifúngico. 
3. MÉTODOS 


\section{Métodos}

A pesquisa foi aprovada pela Comissão de Pesquisa do Departamento de Cardiopneumologia e posteriormente pela Comissão de Ética para a Análise de Projetos de Pesquisa - CAPPesq da Diretoria Clínica do Hospital das Clinicas da Faculdade de Medicina da Universidade de São Paulo, em sessão de 09.05.2007, conforme protocolo n 870/06. O Termo de Consentimento Livre e Esclarecido também foi aprovado no mesmo parecer, nos termos da Resolução do Conselho Nacional de Saúde $n^{\circ} 196$ de 10.10.1996. O termo de consentimento foi assinado pela totalidade dos participantes do estudo, após terem sido informados dos aspectos inerentes ao protocolo de pesquisa e assentido em participar.

\subsection{Seleção dos pacientes}

Foram avaliados para inclusão pacientes consecutivos do Ambulatório de Doenças Intersticiais da Disciplina de Pneumologia da Faculdade de Medicina da Universidade de São Paulo e do Ambulatório de Micoses da Disciplina de Moléstias Infecciosas da Faculdade de Medicina da Universidade de São Paulo no período entre 01 de julho de 2008 a 20 de julho de 2010.

Todos os pacientes foram tratados conforme orientação dos protocolos de assistência dos respectivos ambulatórios e da opinião clínica dos médicos assistentes, seguindo a literatura a respeito de tratamento medicamentoso da paracoccidioidomicose ${ }^{28,76-78}$.

\subsubsection{Critérios de Inclusão}

- Paracoccidioidomicose forma crônica ${ }^{28,} 79$ com diagnóstico comprovado através de critérios histológicos, microbiológicos e/ou sorológicos; 
- Inatividade da doença ${ }^{28,80}$, determinada pelos critérios (presença de todos eles):

- tempo de tratamento maior que seis meses,

- pesquisas microbiológicas negativas,

- resolução das lesões cutâneas e mucosas,

-baixos títulos de anticorpo anti-P. brasiliensis através da contraimunoeletroforese (CIE) ( $<1: 4$ ou queda de pelo menos 4 diluições em relação à inicial)

-ausência de sinais de atividade pela avaliação radiológica;

- Concordância em participar do estudo e assinatura do termo de consentimento livre e esclarecido.

\subsubsection{Critérios de Exclusão}

- Co-infecção respiratória, atual ou prévia, por outro agente infeccioso;

- Neoplasia de pulmão diagnosticada, atual ou prévia;

- Incapacidade em compreender ou realizar os testes previstos no protocolo de pesquisa.

\subsection{Delineamento do estudo}

Estudo prospectivo transversal observacional no qual os pacientes foram submetidos à tomografia computadorizada de alta resolução (TCAR), à prova de função pulmonar completa (PFP), ao teste de caminhada de seis minutos com holter de oximetria (TC6M), ao teste de exercício cardiopulmonar (TECP) e aos questionários de qualidade de vida relacionado à saúde e de índice de dispneia.

A avaliação dos pacientes incluídos no estudo compreendeu, além da obtenção dos dados demográficos (idade, sexo e índice de massa corpórea), a quantificação da exposição tabágica, os títulos da sorologia para paracoccidioidomicose (CIE) no início do tratamento e no período da avaliação, a droga antifúngica utilizada e o tempo de tratamento realizado. 
Os pacientes foram também divididos em dois grupos em relação à gravidade, para buscar variáveis que se relacionassem com um maior impacto na capacidade respiratória após ser atingida a inatividade da doença. $O$ critério de gravidade utilizado foi a dessaturação no teste de caminhada de seis minutos, que foi considerada presente quando a queda da $\mathrm{SpO}_{2}$ final em relação à basal foi maior que $4 \%$, com valores mantidos por pelo menos dez segundos no holter de oximetria ${ }^{81-83}$. Foram dessa forma instituídos dois grupos: Grupo $A=$ mais graves e Grupo $B=$ menos graves.

\subsection{Avaliações realizadas}

\subsubsection{Tomografia de tórax alta resolução}

As tomografias de tórax alta resolução foram obtidas no Instituto de Radiologia do Hospital das Clínicas da Faculdade de Medicina da USP, em um equipamento Multislice Philips Brilliance CT40 (Philips Medical Systems $\AA$, Cleveland, Estados Unidos). Todos os pacientes realizaram cortes em inspiração e em expiração máximas. As alterações foram classificadas conforme Consenso Brasileiro llustrado sobre a Terminologia dos Descritores e Padrões Fundamentais da TC de tórax ${ }^{84}$, segundo modelo apresentado no ANEXO 1. A análise tomográfica dos achados de enfisema centrolobular e parasseptal foi ainda quantificada em quatro graus quanto à sua extensão, conforme descrito a seguir: zero = normal; um = menos que $25 \%$ parênquima; dois = entre 25 e 50\% envolvimento; três = entre 25 e $75 \%$ envolvimento e quatro = mais que $75 \%$ de envolvimento do parênquima ${ }^{85,86}$.

As análises foram realizadas individual e separadamente por um radiologista especializado em tomografia de tórax e por um pneumologista especialista em doenças intersticiais, ambos cegados quanto aos dados 
clínicos dos pacientes. Nos casos em que houve discordância, o resultado final foi obtido em uma reunião de consenso.

\subsubsection{Prova de função pulmonar}

As medidas de fluxos, volumes pulmonares e de difusão através da técnica do monóxido de carbono $\left(\mathrm{DL}_{\mathrm{co}}\right)$, além da ventilação voluntária máxima (VVM), foram realizadas no Laboratório de Função Pulmonar da Divisão de Pneumologia do InCor - HCFMUSP. Todos os pacientes realizaram as medidas em um mesmo aparelho, o pletismógrafo de corpo inteiro Elite $D x$, Elite Series ${ }^{T M}$ Plethysmograph - MedGraphics Cardiorespiratory Diagnostic Systems - Medical Graphics Corporation, INC., 2005, St Paul, MN, USA. O software utilizado foi o Breeze 6.3, e todas as manobras foram realizadas e analisadas de acordo com os critérios da Sociedade Brasileira de Pneumologia e Tisiologia (2002) ${ }^{87}$. Os parâmetros funcionais analisados foram capacidade vital forçada (CVF), volume expiratório forçado no primeiro segundo $\left(\mathrm{VEF}_{1}\right)$, relação $V E F_{1} / C V F$, capacidade pulmonar total (CPT), volume residual (VR), relação VR/CPT e $\mathrm{DL}_{c o}$, além da VVM. Os cálculos utilizados para determinar os valores preditos tiveram como referência a população brasileira ${ }^{88-90}$. Os pacientes foram, ainda, submetidos à espirometria após o uso de broncodilatador (salbutamol inalatório) com os resultados analisados de acordo com os critérios da Sociedade Brasileira de Pneumologia e Tisiologia (2002) ${ }^{87}$.

\subsubsection{Teste de caminhada de seis minutos}

O TC6M, obtido segundo as recomendações da American Thoracic Society (ATS) ${ }^{81}$ e da Sociedade Brasileira de Pneumologia e Tisiologia ${ }^{91}$, foi realizado no prédio dos ambulatórios do Hospital das Clínicas da FMUSP, $2^{\circ}$ 
andar, utilizando um corredor plano de 30 metros demarcado nas extremidades por pinos de sinalização, e a distância caminhada registrada em metros. Foram realizados dois testes, com intervalo mínimo de vinte minutos, nos pacientes que não haviam realizado essa avaliação prévia. A escala de Borg para avaliação de dispneia e fadiga de membros inferiores foi aplicada antes e imediatamente ao final do teste ${ }^{92}$ (ANEXO 1). Foi utilizado um holter de oximetria da marca NONIN WristOx 3100 (Plymouth, MN, EUA) com sensor do tipo PureLight LED, e os dados obtidos analisados através do nVISION software (Plymouth, MN, EUA). Os cálculos utilizados para determinar os valores preditos tiveram como referência a população brasileira ${ }^{91}$. Foram utilizados para cálculo a distância percorrida e a $\mathrm{SpO}_{2}$ obtida através do holter, com o valor de $\mathrm{SpO}_{2}$ sendo considerado quando mantido por no mínimo 10 segundos $^{81,82}$.

\subsubsection{Teste de exercício cardiopulmonar}

Os pacientes foram submetidos aos testes de exercício cardiopulmonar ou testes ergoespirométricos no Laboratório de Função Pulmonar da Divisão de Pneumologia do InCor - HCFMUSP (altitude de 680 m). O aparelho utilizado pela totalidade dos pacientes foi o Ciclo-ergômetro modelo Lode Corival - Lode B.V. Medical Technology, Groningen, The Netherlands, com o sistema $\mathrm{CardiO}_{2}$ (CPX MedGraphics Corporation - MGC - St Paul, MN, USA), composto por um módulo analisador de gases (Module GAS CE) acoplado a um módulo de fluxo (Flow Module CE), e por um microcomputador, que capta os sinais provenientes do ciclo-ergômetro. Acoplado ao sistema, há um eletrocardiograma de 12 derivações (Cardio Perfect PC-Based 12 Lead ECG, Welch Allyn, INC., Skaneateles Falls, NY, USA). A Saturação periférica de oxigênio ( $\mathrm{SpO} 2)$ foi aferida através de um oxímetro NONIN Onyx, Model 9500 - (Nonin Medical, INC., Plymouth, MN, USA). 
Os testes foram realizados na bicicleta ergométrica utilizando-se um protocolo incremental em rampa (10 a $20 \mathrm{watts} / \mathrm{min}$, determinado pelo pesquisador de acordo com estimativa da aptidão física dos pacientes). $\mathrm{O}$ teste consistiu de uma fase de repouso (2 min), seguida por uma fase de aquecimento sem carga (2 min) e então de exercício incremental, sendo interrompido por exaustão, fadiga ou dispneia, dando início ao período de recuperação (3 min). A cada 2 minutos foi aplicada a escala de Borg modificado até o pico de exercício para a avaliação dos sintomas respiratórios e fadiga dos membros inferiores.

A cada ciclo ventilatório ("respiração por respiração"), foram mensurados o consumo de oxigênio $\left(\mathrm{VO}_{2}\right)$, a produção de dióxido de carbono $\left(\mathrm{VCO}_{2}\right)$, a ventilação minuto $(\mathrm{VE}, \mathrm{L} / \mathrm{min})$, a frequência respiratória (f, $\mathrm{rpm})$ e o equivalente ventilatório para o $\mathrm{O}_{2}$ e $\mathrm{CO}_{2}\left(\mathrm{VE} / \mathrm{VO}_{2}\right.$ e $\left.\mathrm{VE} / \mathrm{VCO}_{2}\right)$. $\mathrm{O}$ eletrocardiograma com 12 derivações e a saturação periférica de oxigênio foram monitorados continuamente, e a cada dois minutos foi realizada a mensuração da capacidade inspiratória $(\mathrm{Cl})$.

Para a análise dos resultados foi considerado $\circ \mathrm{VO}_{2}$ no pico de exercício $\left(\mathrm{VO}_{2}\right.$ pico), que foi a média do consumo de oxigênio nos últimos 20 segundos antes da interrupção do teste. A reserva ventilatória foi calculada através da razão entre a ventilação minuto no pico do exercício e a ventilação voluntária máxima (VE/VVM). Os cálculos utilizados para determinar os valores preditos tiveram como referência a população brasileira ${ }^{93,94}$.

\subsubsection{Questionários de dispneia e qualidade de vida}

Os pacientes responderam ao questionário de dispneia do Medical Research Council (MRC) modificado ${ }^{95-97}$ (ANEXO 3) e ao Questionário do Hospital Saint George na Doença Respiratória (SGRQ) (ANEXO 4) ${ }^{98,99}$. O $S G R Q$ é um questionário doença-específico respiratório que aborda os aspectos relacionados a três domínios: sintomas, atividade e impactos psicossociais que a doença respiratória inflige ao paciente. Cada domínio 
tem uma pontuação máxima possível; os pontos de cada resposta são somados e o total é referido como um percentual deste máximo. Valores acima de $10 \%$ refletem uma qualidade de vida alterada naquele domínio ${ }^{99}$.

A escala do MRC é composta por apenas cinco itens, sendo que o paciente escolhe $o$ item que corresponde a quanto a dispneia limita suas atividades da vida diária. $O$ paciente relata seu grau subjetivo de dispneia escolhendo um valor entre 1 e 5: 1 (só sofre de falta de ar durante exercícios intensos), 2 (sofre de falta de ar quando andando apressadamente ou subindo uma rampa leve), 3 (anda mais devagar do que pessoas da mesma idade por causa de falta de ar ou tem que parar para respirar mesmo quando andando devagar), 4 (pára para respirar depois de andar menos de $100 \mathrm{~m}$ ou após alguns minutos) e 5 (sente tanta falta de ar que não sai mais de casa, ou sente falta de ar quando está se vestindo) ${ }^{96,97}$.

\subsection{Análise Estatística}

A análise estatística foi realizada utilizando o software GraphPad Prism version 5.00 for Windows, GraphPad Software, San Diego California USA.

As variáveis paramétricas, definidas pelo teste de normalidade de D'Agostinho e Pearson, foram expressas em média e desvio-padrão (DP), e as variáveis não paramétricas foram expressas através de mediana e intervalo interquartil (IQ).

As correlações foram realizadas através dos testes de Spearman ou Pearson, a depender da distribuição normal ou não normal das variáveis contínuas. Variáveis categóricas foram comparadas utilizando-se o teste Exato de Fisher ou teste chi-quadrado, conforme apropriado. As variáveis paramétricas foram comparadas por teste $t$ de Student, e as variáveis não paramétricas comparadas utilizando 0 teste de Mann-Whitney. A significância estatística foi assumida para valores de $p<0,05$. 
4. RESULTADOS 


\subsection{Casuística e características clínico-demográficas}

No período de julho de 2008 a julho de 2010, foram avaliados 73 pacientes consecutivos com diagnóstico de Paracoccidioidomicose em acompanhamento nos Ambulatórios de Doenças Intersticiais (Disciplina de Pneumologia) e de Micoses Sistêmicas (Disciplina de Moléstias Infecciosas) do HC-FMUSP. Destes, 50 apresentaram critérios de inclusão e completaram 0 protocolo. Foram excluídos 23 pacientes: 10 por apresentarem a forma juvenil da PCM, 7 por co-infecção por tuberculose, 4 por incapacidade de realizar os testes funcionais e 2 por recusa.

As características clínico-demográficas, assim como os dados da sorologia ( $\mathrm{CIE})$ dos 50 pacientes estão evidenciadas na Tabela 1. As informações relativas às medicações utilizadas no tratamento estão demonstradas na Figura 1. Dos 50 pacientes, 54\% ainda estavam recebendo medicação antifúngica, porém em regime considerado de manutenção. 
Tabela 1 - Dados clínico - demográficos dos 50 pacientes avaliados

Idade em anos $\pm \mathrm{DP}$

$56,9 \pm 9,7$

Sexo

47 homens : 3 mulheres

Índice de massa corpórea (IQ)

$23(20-26)$

Tabagismo ativo ou prévio (\%)

$49(98 \%)$

- Ativo (\%)

$29(58 \%)$

Carga tabágica em anos-maço \pm DP

$37 \pm 20$

Tempo de tratamento em meses $(\mathrm{IQ})$

$29(18-58)$

Intervalo (em anos) entre início tratamento e avaliação $\pm D P$

$5,9 \pm 3,8$

Sorologia (CIE) inicial (IQ)

$1: 64(1: 16-1: 256)$

Sorologia (CIE) ao protocolo (IQ)

$1: 2(0-1: 4)$

Valores distribuídos em valor absoluto (\%); média \pm DP ou mediana (IQ). \% = porcentagem; $\mathrm{DP}=$ desvio padrão; $I Q$ = interquartil 


\section{Figura 1}

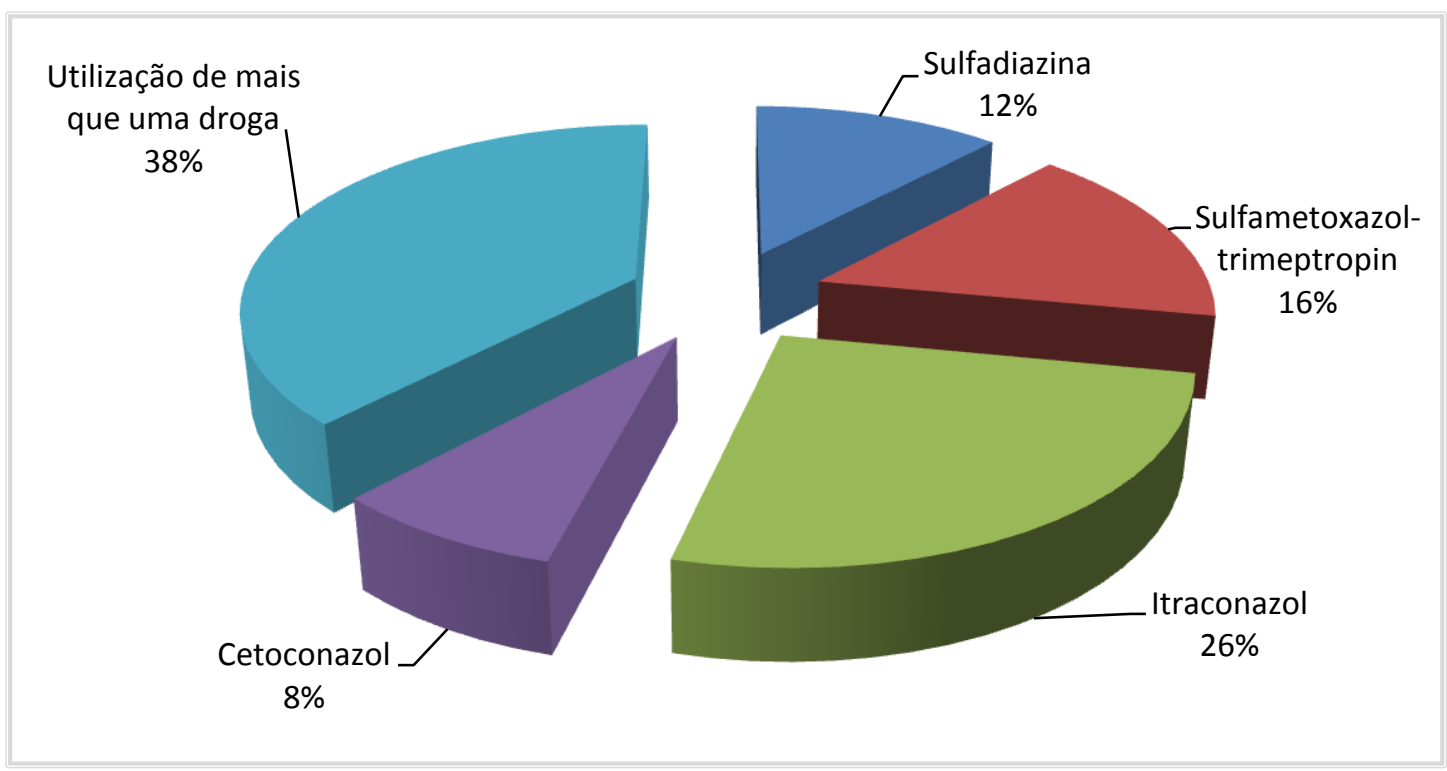

Fig.1 Dados relacionados às medicações antifúngicas utilizadas pelos 50 pacientes. 


\subsection{Tomografia de tórax alta resolução}

A tomografia de tórax de alta resolução mostrou-se alterada (pelo menos uma alteração) em $98 \%$ dos casos, e frequentemente anormalidades distintas estavam presentes em um mesmo paciente (mediana de 9 alterações por paciente).

Os achados tomográficos dos 50 pacientes encontram-se nas tabelas 2, 3 e 4, seguidos de figuras com cortes tomográficos exemplificando as principais alterações radiológicas na coorte estudada.

As principais alterações encontradas tiveram distribuição preponderantemente difusa (uma ou mais zonas pulmonares), predominando nos lobos superiores e médios, e com associação das localizações central e periférica. 
Tabela 2 - Resultados da tomografia de tórax de alta resolução

\begin{tabular}{lcc}
\hline Achado & $\mathbf{n}$ & \% total \\
\hline Distorção da arquitetura / opacidades retráteis & 45 & 90 \\
\hline Reticulado / espessamento septal & 44 & 88 \\
\hline Enfisema centrolobular e/ou parasseptal & 41 & 82 \\
\hline Espessamento brônquico & 41 & 82 \\
\hline Banda parenquimatosa & & \\
\hline Enfisema paracicatricial & 37 & 74 \\
\hline
\end{tabular}

Espessamento interstício peribroncovascular $\quad 31 \quad 62$

Nódulo (até $3 \mathrm{~cm}$ ) $\quad 31 \quad 62$

Opacidade em vidro fosco

$23 \quad 46$

Bronquiectasia e/ou bronquiolectasia

22

44

Alteração pleural

10

20 
Linfonodomegalia

3

6

Consolidação

Cavitação

Aprisionamento aéreo (expiração)

Pelo menos 1 alteração
2

4

1

2

38

76

49

98 
Tabela 3 - Distribuição dos achados principais da tomografia de tórax

\begin{tabular}{lcc}
\hline Localização / zonas & $\mathbf{n}$ & \% total \\
\hline Central & 4 & 8 \\
Periférica & 6 & 12 \\
\hline $\begin{array}{l}\text { Central + periférica } \\
\text { Superior (acima carina) }\end{array}$ & 40 & 80 \\
\hline $\begin{array}{l}\text { Médio (carina - veias pulmonares } \\
\text { inferiores) }\end{array}$ & 24 & 48 \\
\hline Inferior (abaixo veias pulmonares) & 22 & 44 \\
\hline Difuso (combinação de 2 ou + zonas) & 42 & 84 \\
\hline
\end{tabular}


Tabela 4 - Quantificação do enfisema quanto ao grau de extensão

\begin{tabular}{lcc}
\hline Achado / grau de extensão & $\mathbf{n}$ & \% total \\
\hline Enfisema centrolobular e/ou parasseptal & 9 & 18 \\
$\mathbf{0}$ & 15 & 30 \\
$\mathbf{+}$ & 12 & 24 \\
$\mathbf{+ +}$ & 13 & 26 \\
$\mathbf{+ + +}$ & 1 & 2 \\
$\mathbf{+ + + +}$ & & \\
$\mathbf{E n f i s e m a ~ p a r a c i c a t r i c i a l ~}$ & & 34 \\
$\mathbf{0}$ & 17 & 44 \\
+ & 22 & 22 \\
++ & 11 & 0 \\
+++ & 0 & 0 \\
\hline++++ & 0 & \\
\hline
\end{tabular}




\subsubsection{Padrões das Tomografias de tórax em alta resolução}

\section{Figura 2}

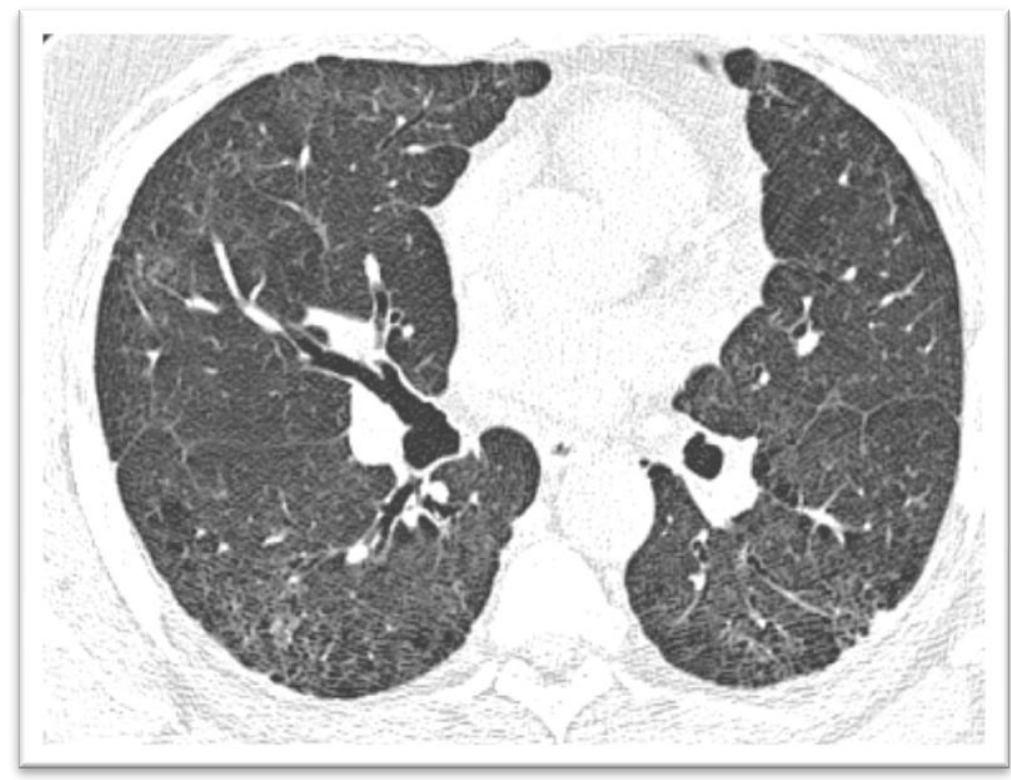

Fig.2 TCAR ao nível dos lobos superiores mostrando espessamento septal e reticulado de distribuição periférica

\section{Figura 3}

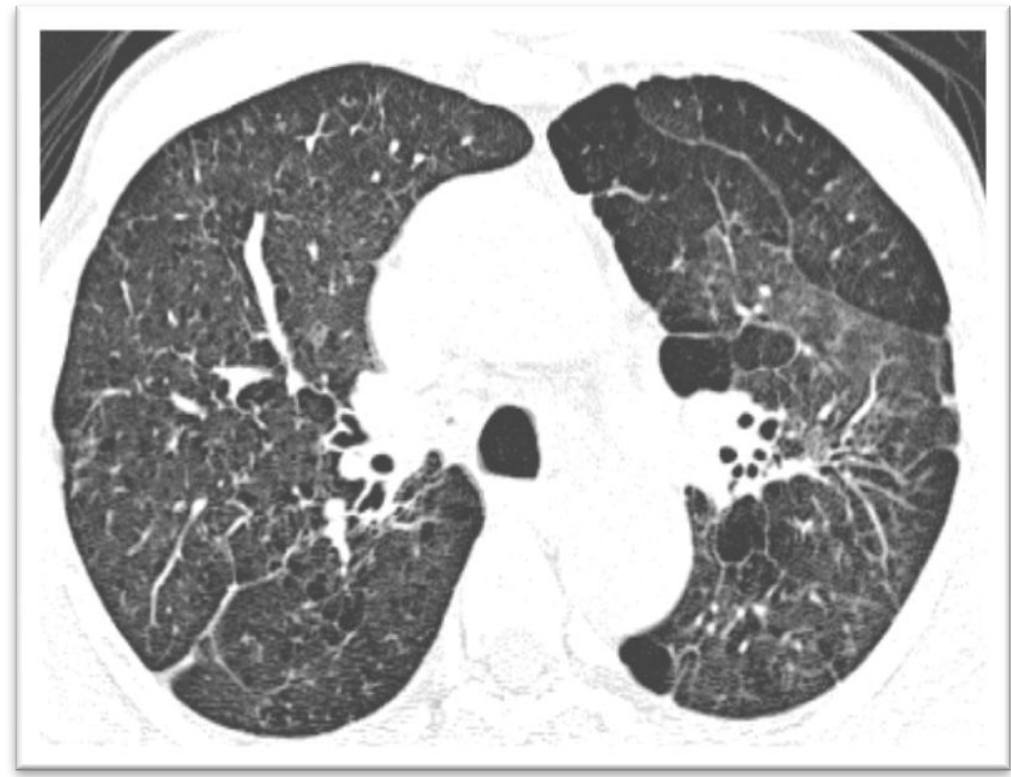

Fig.3 TCAR ao nível dos lobos superiores evidenciando distorção da arquitetura 


\section{Figura 4}

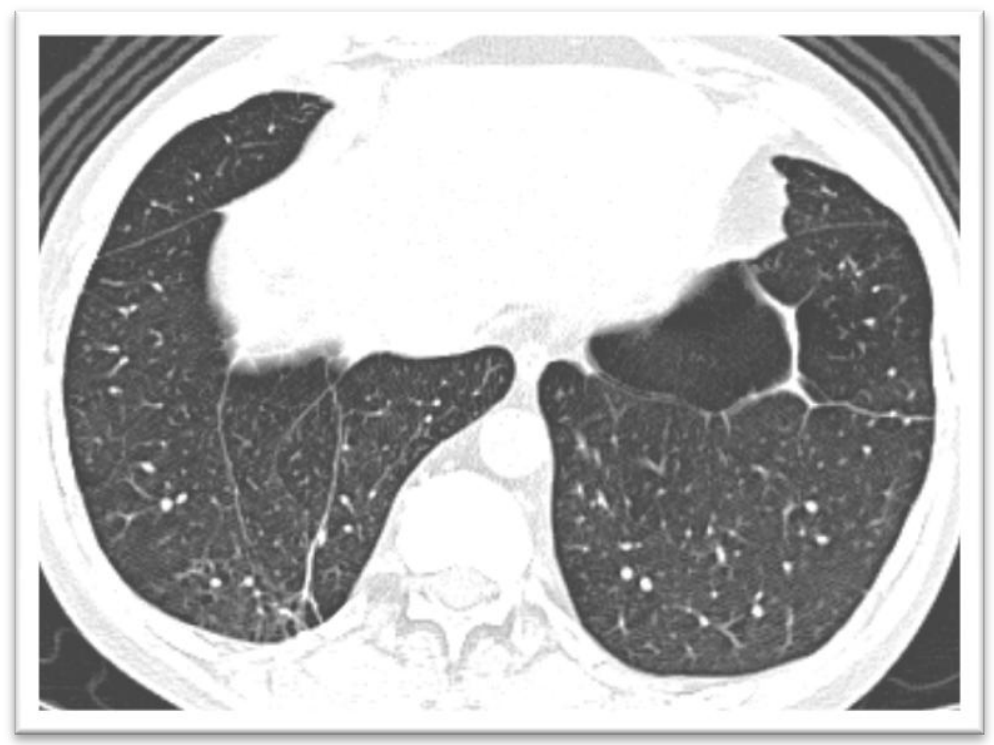

Fig.4 TCAR ao nível dos lobos inferiores demonstrando bandas parenquimatosas

\section{Figura 5}

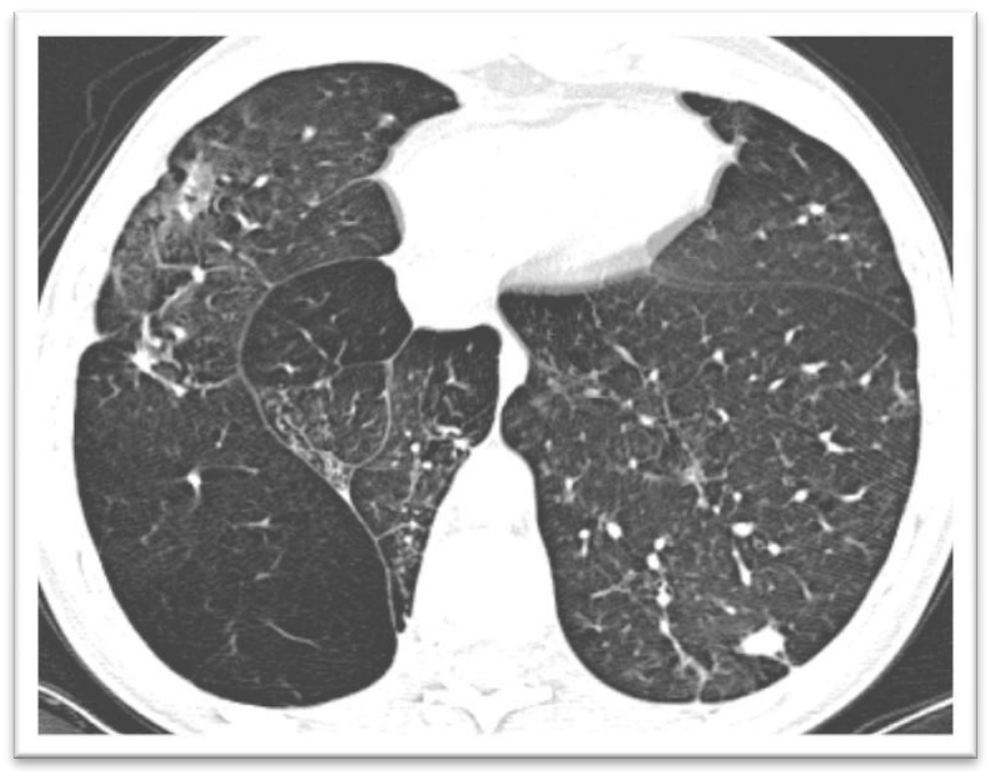

Fig.5 TCAR ao nível dos lobos inferiores exemplificando nódulo em lobo inferior esquerdo, e foco de vidro fosco no lobo inferior direito 


\section{Figura 6}

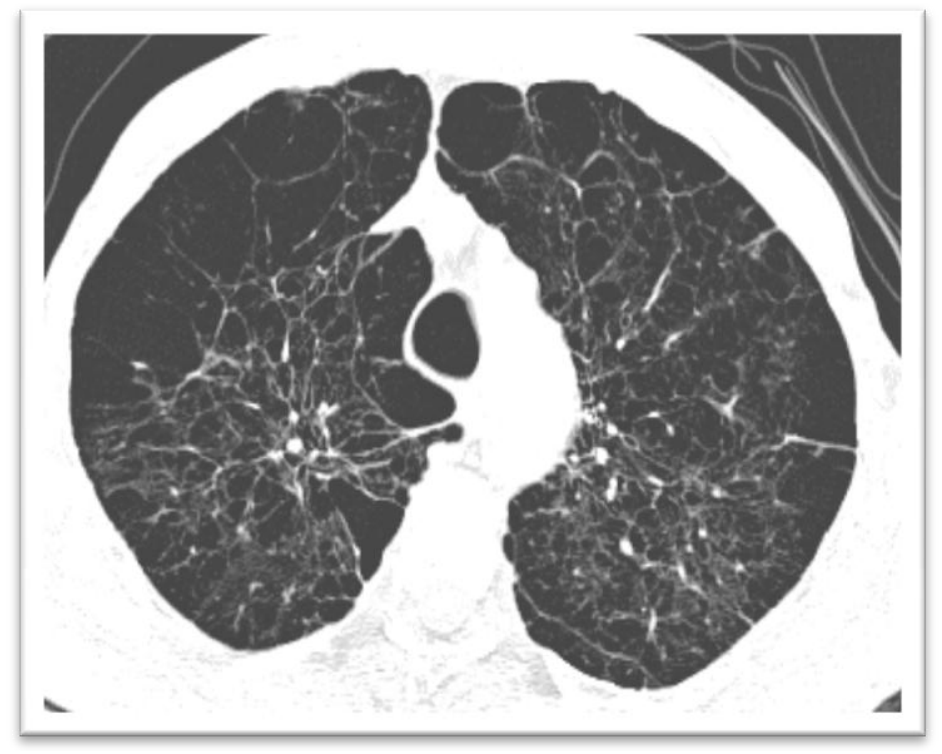

Fig.6 TCAR ao nível dos lobos superiores evidenciando enfisema centrolobular e parasseptal

\section{Figura 7}

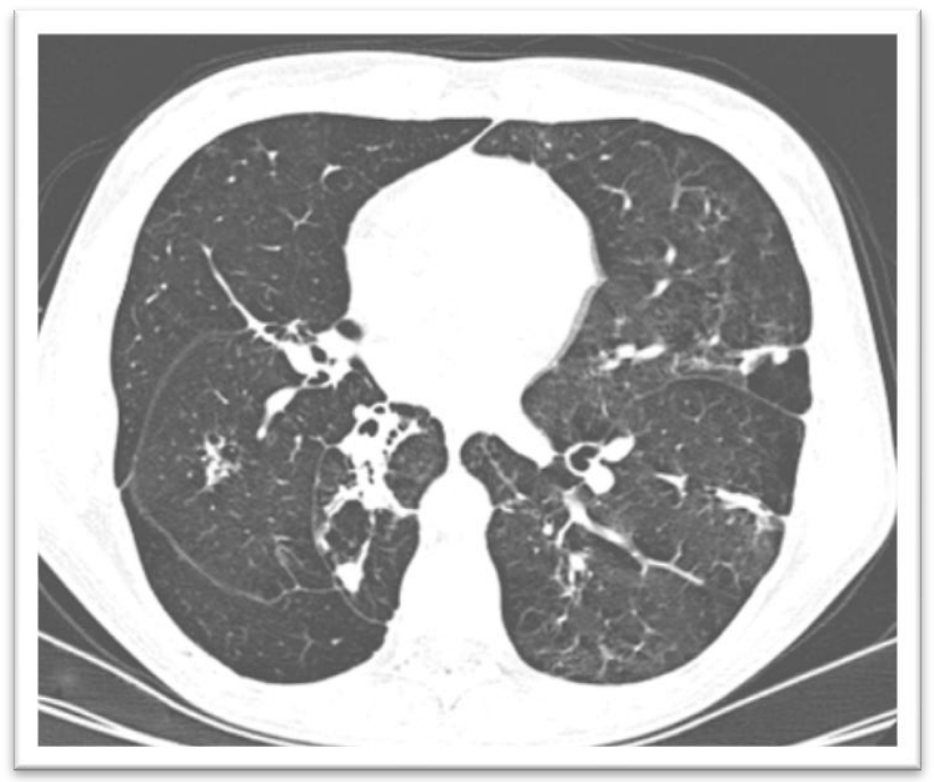

Fig.7 TCAR ao nível dos lobos inferiores com áreas de espessamento do interstício peribroncovascular 


\section{Figura 8}

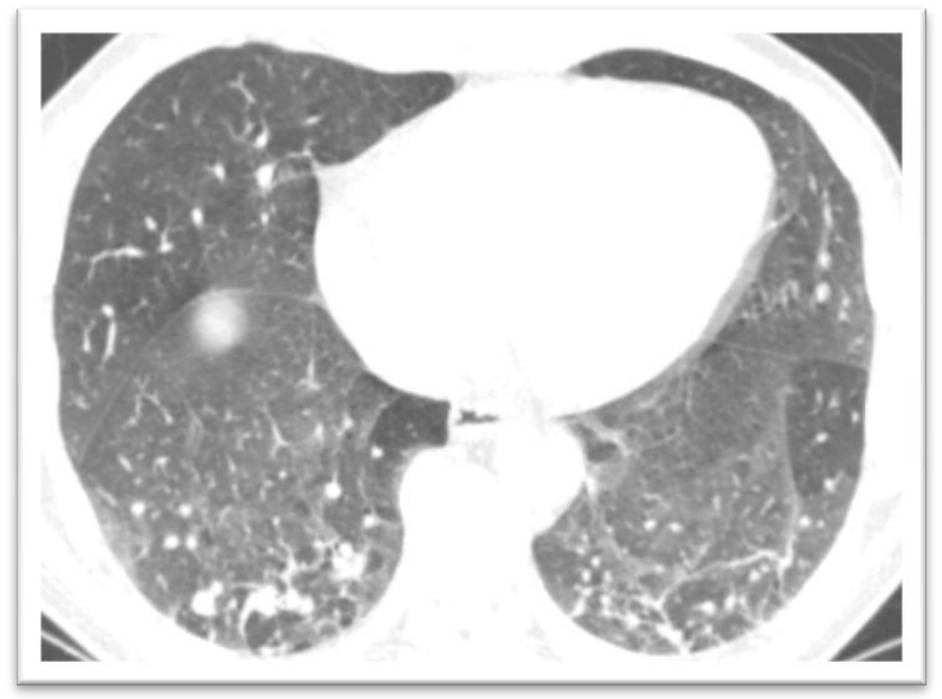

Fig.8 TCAR em expiração com padrão em mosaico, evidenciando áreas de aprisionamento aéreo em lobos inferiores

\subsection{Avaliações funcionais}

\subsubsection{Prova de função pulmonar}

Dos 50 pacientes avaliados, três não realizaram medidas de capacidades pulmonares (pletismografia). A espirometria após uso de broncodilatador foi realizada na totalidade dos 50 pacientes.

A média dos resultados mostrou um distúrbio obstrutivo leve não responsivo a broncodilatador com redução dos fluxos médios e redução leve a moderada da $D L_{c o}$, além de discreta redução da VVM, conforme os dados demonstrados nas Tabelas 5 e 6 .

Dos 50 pacientes, 35 (70\%) apresentaram padrão obstrutivo com $\mathrm{VEF}_{1} / \mathrm{CVF}<0,70,14$ (28\%) volumes e capacidades normais e apenas um (2\%) apresentou padrão restritivo (CPT < 80\% com VEF $1 / C V F$ normal). Dos pacientes com distúrbio obstrutivo, 30 (85\%) tiveram distúrbio leve 
(VEF $1>60 \%$ do esperado), 4 (11\%) distúrbio moderado $\left(40 \%<\mathrm{VEF}_{1}<60 \%\right)$ e apenas 1 paciente distúrbio grave $\left(\operatorname{VEF}_{1}<40 \%\right)$.

Em relação à DLco, 9 pacientes (18\%) apresentaram distúrbio grave (DLco <40\%), 15 (30\%) distúrbio moderado (40\%< DLco <60\%), 19 (38\%) distúrbio leve (DLco > 60\%) e 7 (14\%) dos pacientes apresentaram difusão normal (DLCo $>80 \%)$. 
Tabela 5 - Resultados das análises dos volumes, fluxos e capacidades pulmonares, difusão e ventilação voluntária máxima dos pacientes avaliados

\begin{tabular}{|c|c|c|c|}
\hline Variável (n) & Valor \pm DP & $\begin{array}{c}\% \text { predito } \pm \\
\text { DP }\end{array}$ & LIN \\
\hline CVF (L) (50) & $4,00 \pm 0,82$ & $95 \pm 12$ & 3,31 \\
\hline $\operatorname{VEF}_{1}(L)(50)$ & $2,60 \pm 0,68$ & $77 \pm 17$ & 2,62 \\
\hline VEF $_{1} /$ CVF (50) & $0,65 \pm 0,11$ & $82 \pm 13$ & 72 \\
\hline $\mathrm{FEF}_{25-75 \%}(\mathrm{~L} / \mathrm{s})(50)$ & $1,6 \pm 0,93$ & $52 \pm 28$ & 1,83 \\
\hline CPT (L) (47) & $6,80 \pm 0,20$ & $100 \pm 13$ & \\
\hline VR (L) (47) & $2,40 \pm 0,73$ & $121 \pm 35$ & \\
\hline VR / CPT (47) & $0,38 \pm 0,07$ & $117 \pm 23$ & \\
\hline $\mathrm{DL}_{\mathrm{co}}(\mathrm{mL} / \mathrm{min} / \mathrm{mmHg})(50)$ & $20 \pm 6$ & $61 \pm 20$ & 26 \\
\hline VVM (L/min) (50) & $102 \pm 26$ & $76 \pm 16$ & 95 \\
\hline \multicolumn{4}{|c|}{$\begin{array}{l}\text { Valores distribuídos em média } \pm \mathrm{DP} . \mathrm{n}=\text { número de pacientes; } \mathrm{CVF}=\text { capacidade vital } \\
\text { forçada; } \mathrm{VEF} \mathrm{F}_{1}=\text { volume expirado ao final do primeiro segundo; } \mathrm{FEF}=\text { fluxo expiratório } \\
\text { máximo; } \mathrm{CPT}=\text { capacidade pulmonar total; } \mathrm{VR}=\text { volume residual; } \mathrm{DLCO}=\text { difusão de } \\
\text { monóxido de carbono; } \mathrm{VR}=\text { volume residual; } \mathrm{VVM}=\text { ventilação voluntária máxima; } \\
\text { LIN=limite inferior da normalidade }\end{array}$} \\
\hline
\end{tabular}


Tabela 6 - Resultados dos volumes e fluxos pulmonares, após uso de broncodilatador (BD)

\begin{tabular}{lccc}
\hline & Pré BD & Pós BD & \\
\hline Valor \pm DP & Valor \pm DP & \\
\hline \% predito (DP) & $\%$ predito \pm DP & $\%$ resposta \\
& $4,00 \pm 0,82$ & $3,97 \pm 0,89$ & \\
CVF (L) & $95 \pm 12$ & $95 \pm 23$ & $1,2 \pm 4,8$ \\
& $2,60 \pm 0,68$ & $2,73 \pm 0,68$ & \\
VEF $_{1}$ (L) & $77 \pm 17$ & $82 \pm 20$ & $5,6 \pm 6,0$ \\
& & & \\
VEF $_{1} /$ CVF & $0,65 \pm 0,11$ & $0,69 \pm 0,10$ & \\
& $82 \pm 13$ & $87 \pm 13$ & $4,2 \pm 4,8$
\end{tabular}

Valores distribuídos em média \pm DP. CVF = capacidade vital forçada; $V E F_{1}=$ volume expirado ao final do primeiro segundo 


\subsubsection{Teste de caminhada de seis minutos}

Os resultados do teste de caminhada de seis minutos dos 50 pacientes estudados estão descritos na Tabela 7 .

Tabela 7 - Resultados do teste de caminhada de seis minutos

$\%$ predito (IQ)

Distância (metros)

$492(456-520) \quad 131(121-143)$

$\mathrm{SpO}_{2}$

- Início

$96 \pm 1,6$

- Término

$93 \pm 4$

$\%$ Diferença $\mathrm{SpO}_{2}$ (inicial - final)

$2(1-4)$

Valores distribuídos em media \pm DP ou mediana (IQ). DP = desvio padrão; IQ = interquartil

\subsubsection{Teste de exercício cardiopulmonar}

As tabelas 8 e 9 apresentam os principais resultados da ergoespirometria encontrados na nossa casuística. O principal motivo da interrupção do TCPE foi fadiga ou dor nos membros inferiores.

Houve uma correlação positiva entre o consumo máximo de oxigênio e a distância caminhada no TC6M, conforme mostrado na figura 9. 
Tabela 8 - Resultados do teste de exercício cardiopulmonar I

\begin{tabular}{|c|c|c|}
\hline Variável & Valor (DP) & $\%$ predito (DP) \\
\hline Carga máx (w) & $109 \pm 37$ & $88 \pm 28$ \\
\hline $\mathrm{VO}_{2} \operatorname{máx}(\mathrm{mL} / \mathrm{kg} / \mathrm{min})$ & $22 \pm 6$ & $81 \pm 19$ \\
\hline \multicolumn{3}{|l|}{ FC (bpm) } \\
\hline - Repouso & $77 \pm 15$ & \\
\hline - Pico exercício & $133 \pm 22$ & $82 \pm 13$ \\
\hline $\mathrm{VO}_{2} / \mathrm{FC}$ (pico do exercício) & $11 \pm 2,8$ & $103 \pm 26$ \\
\hline \multicolumn{3}{|l|}{ VE (L/min) } \\
\hline - Repouso & $13 \pm 4,9$ & \\
\hline - Pico do exercício & $60 \pm 20$ & $68 \pm 20$ \\
\hline $\mathrm{VE} / \mathrm{VCO}_{2}$ (no limiar anaeróbio) & $36 \pm 8$ & $102 \pm 20$ \\
\hline $\mathrm{AT} / \mathrm{VO}_{2}$ máx pred & $51 \pm 16$ & $96 \pm 32$ \\
\hline VE / VVM & $0,60 \pm 17$ & \\
\hline \multicolumn{3}{|l|}{ RER } \\
\hline - Repouso & $0,94 \pm 0,12$ & \\
\hline - Pico do exercício & $1,2 \pm 0,12$ & \\
\hline
\end{tabular}

Valores distribuídos em média $\pm \mathrm{DP}$. $\mathrm{FC}=$ freqüência cardíaca; $\mathrm{VO}_{2}=$ consumo de oxigênio; $\mathrm{VE}=$ volume minuto expirado; $\mathrm{VCO}_{2}=$ liberação de dióxido de carbono; $\mathrm{AT}=$ limiar anaeróbico; VVM = ventilação voluntária máxima; RER=taxa de troca gasosa 
Tabela 9 - Resultados do teste de exercício cardiopulmonar II

\begin{tabular}{ll}
\hline Variável & Valor \pm DP \\
\hline Diferença Cl inicial - final (\%) & $9 \pm 5,3$ \\
BORG (pico do exercício) & \\
- Dispneia & $6,5 \pm 3-9$ \\
$\bullet \quad$ Fadiga mmii & $6,5 \pm 3-7$ \\
SpO 2 & \\
$\bullet \quad$ Repouso (IQ) & $97(96-98)$ \\
- Pico do exercício (IQ) & $94(92-96)$ \\
\hline
\end{tabular}

Valores distribuídos em média (DP) ou mediana (IQ). DP = desvio padrão; IQ = interquartil; $\%$ =porcentagem; $\mathrm{Cl}$ = capacidade inspiratória; $\mathrm{SpO}_{2}=$ saturação periférica de oxigênio 


\section{Figura 9}

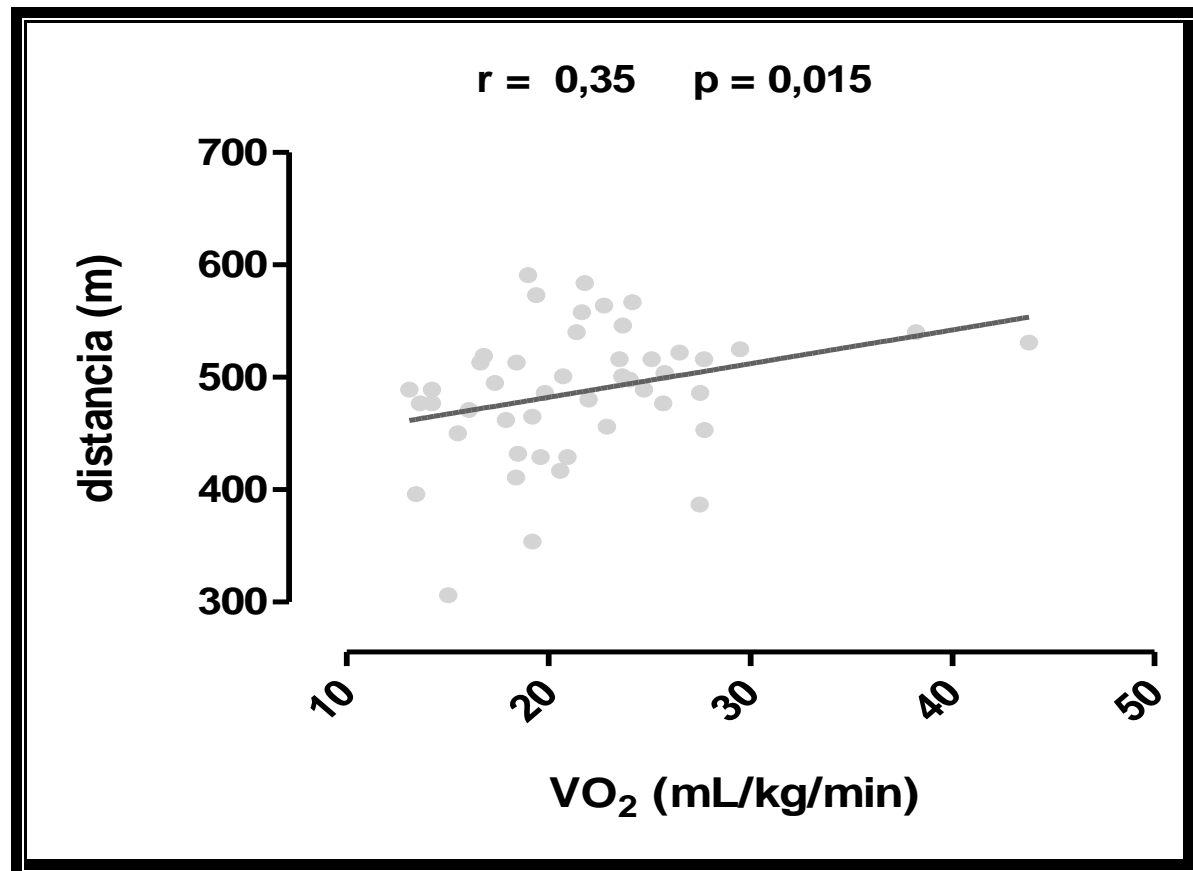

Fig 9. Valores de $\mathrm{VO}_{2}(\mathrm{~mL} / \mathrm{kg} / \mathrm{min})$ mostrando relação positiva com a distância, em metros, do teste de caminhada de seis minutos

\subsection{Avaliação da qualidade de vida e do índice de dispneia}

Os 50 pacientes foram avaliados em relação aos três domínios do Questionário do Hospital Saint George na Doença Respiratória (sintomas, atividade e impactos psicossociais) e obtiveram as pontuações descritas na Tabela 10. Os domínios do SGRQ que os pacientes apresentaram pior desempenho foram de sintomas e atividade.

$\mathrm{Na}$ Tabela 11, estão demonstrados os resultados da escala de dispneia de MRC.

Houve boa correlação entre as duas avaliações, com $r=0,65 \mathrm{e}$ $\mathrm{p}<0,0001$. 
Tabela 10 - Pontuação no Questionário do Hospital Saint George na Doença Respiratória

Domínios

Pontuação

Sintomas

Total de pontos (IQ)

$118,2(24,93-231,6)$

$\%$ total (IQ)

$17,85(3,72-34,98)$

Atividade

Total de pontos (IQ)

$356,6(69,95-505)$

$\%$ total (IQ)

$29,5(5,82-41,80)$

Impacto

Total de pontos (IQ)

$68,45(0-273,9)$

$\%$ total (IQ)

$3,25(0-12,95)$

TOTAL (DP)

$648(552,3)$

\% total (DP)

$16,25(13,84)$

Valores distribuídos em média (DP) ou mediana (IQ). DP = desvio padrão; IQ = interquartil

Tabela 11 - Resultados do Questionário do Medical Research Council

$\operatorname{MRC~(IQ)~} \quad 1(1-2)$

Valores distribuídos em mediana (IQ). IQ = interquartil 


\subsubsection{Correlações das variáveis avaliadas com a sorologia inicial}

Os títulos da CIE representam uma medida indireta na resposta imune individual e potencialmente da gravidade da doença, por isso foi pesquisada correlação entre a CIE e as variáveis clínicas e funcionais do estudo.

A correlação entre valores da sorologia inicial e difusão de monóxido de carbono mostrou-se significante com $r=-0,44$ e $p=0,001$; assim como a relação entre a sorologia inicial e o questionário de qualidade de vida em relação à saúde, com $r=0,33$ e $p=0,021$. Não houve, entretanto, relação dos valores da sorologia ao diagnóstico e outros parâmetros funcionais ou tomográficos entre os pacientes estudados.

\subsection{Comparação entre dois grupos A e B divididos quanto a gravidade medida pela dessaturação ao TC6M}

Através da análise dos resultados dos cinquenta pacientes avaliados, encontrou-se a parcela dos indivíduos que apresentavam maior déficit de troca gasosa no exercício, caracterizando um maior impacto na capacidade respiratória após tratamento antifúngico. Um exemplo de paciente com presença de dessaturação no TC6M é ilustrado na figura 10.

Os pacientes, divididos quanto à presença ou não de dessaturação no TC6M (considerada pela presença de queda da $\mathrm{SpO}_{2}>4 \%$ em relação à $\mathrm{SpO}_{2}$ basal com valor mantido por pelo menos 10 segundos no holter de oximetria), foram assim ajuntados nos dois grupos $\mathrm{A}$ e $\mathrm{B}$, nomeados como mais graves (grupo A) e menos graves (grupo B). Com isso, foi feita a comparação do grupo mais grave com o restante da população do estudo.

As características clínico-demográficas e os dados da CIE dos pacientes separados nos dois grupos seguindo o critério de gravidade estão expostos na Tabela 12.

Não houve diferença significativa entre as medicações antifúngicas utilizadas entre os dois grupos ( $p>0,05)$. 
Figura 10 - Holter de oximetria de paciente com intensa dessaturação no TC6M, ilustrada através do gráfico de $\mathrm{SpO}_{2}$ pelo tempo do teste.

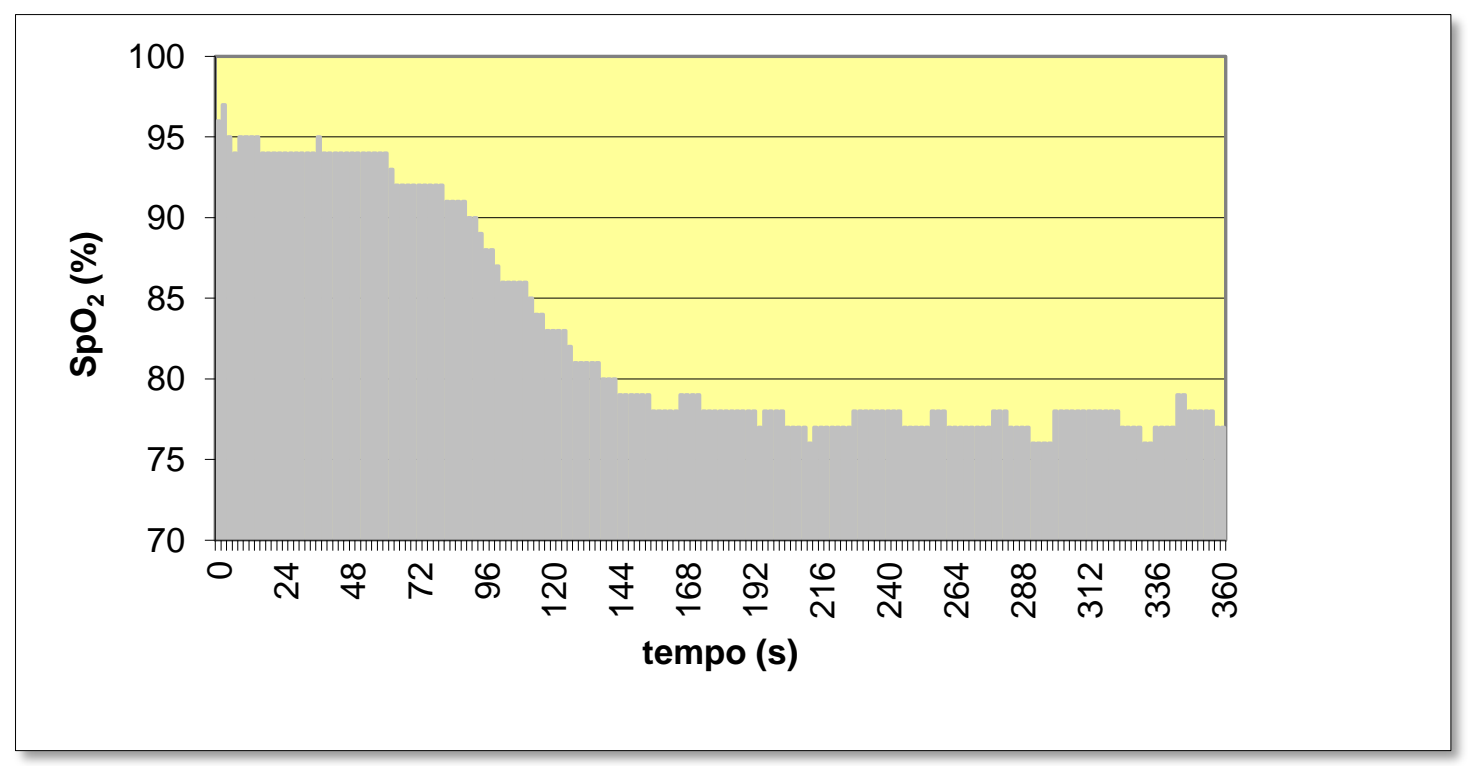


Tabela 12 - Dados clínico - demográficos dos dois grupos (A x B)

\begin{tabular}{|c|c|c|c|}
\hline & $\begin{array}{c}\text { GRUPO A } \\
(n=18)\end{array}$ & $\begin{array}{l}\text { GRUPO B } \\
(n=32)\end{array}$ & $p(A \times B)$ \\
\hline Idade em anos \pm DP & $59,1 \pm 2,2$ & $55,6 \pm 1,7$ & 0,21 \\
\hline Índice de massa corpórea \pm DP & $24,7 \pm 1,4$ & $23,6 \pm 0,6$ & 0,50 \\
\hline Carga tabágica em anos/maço (IQ) & $30(20-42)$ & $37(30-53)$ & 0,25 \\
\hline $\begin{array}{l}\text { Tempo de tratamento em meses } \\
\text { (IQ) }\end{array}$ & $22(12-52)$ & $33(20-66)$ & 0,13 \\
\hline Sorologia (CIE) inicial (IQ) & 1: 128 & 1:32 & 0,01 \\
\hline & $(1: 128-1: 256)$ & $(1: 8-1: 128)$ & \\
\hline
\end{tabular}

Valores distribuídos em valor absoluto (\%); média \pm DP ou mediana (IQ). \% = porcentagem; $\mathrm{DP}=$ desvio padrão; $\mathrm{IQ}=$ interquartil 
Em relação ao número de anormalidades tomográficas, a comparação não revelou diferença significativa no entre os dois grupos $A$ e $B$, com o grupo $A$ apresentando uma média de 8 alterações por paciente, e o grupo $B$ um total médio de 7 alterações tomográficas descritas (Figura 10, $p=0,70$ ).

Tampouco as alterações fibróticas cicatriciais (Distorção da arquitetura/opacidades retráteis, reticulado/espessamento septal e bandas parenquimatosas), estiveram mais presentes em um grupo em relação ao outro (Figura 12, $\mathrm{p}=0,85$ ).

Houve, entretanto, maior grau de enfisema centrolobular e parasseptal no grupo B em relação ao grupo $A$ (Figura 13, $p=0,0009$ ).

Figura 11 - Comparação entre o número de alterações tomográficas nos grupos A e B

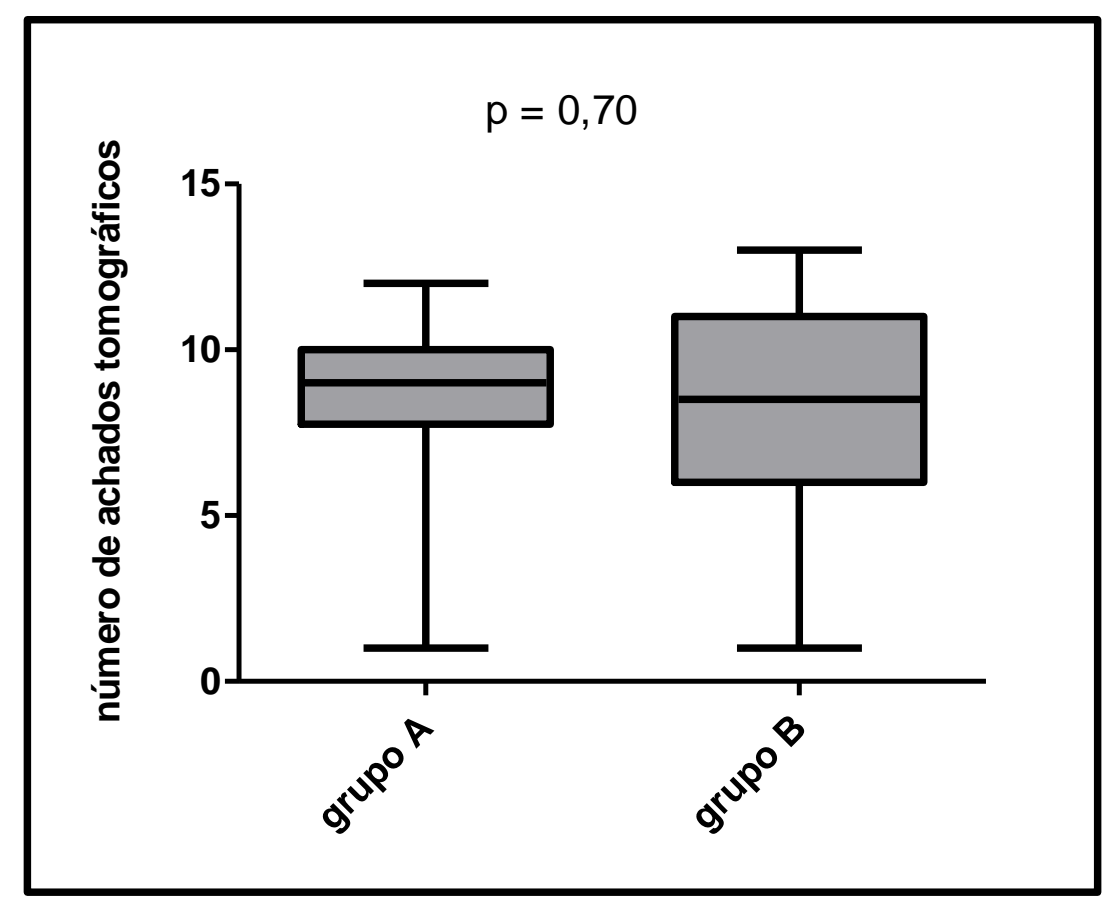


Figura 12 - Comparação entre a incidência de alterações fibróticas nos grupos A e B

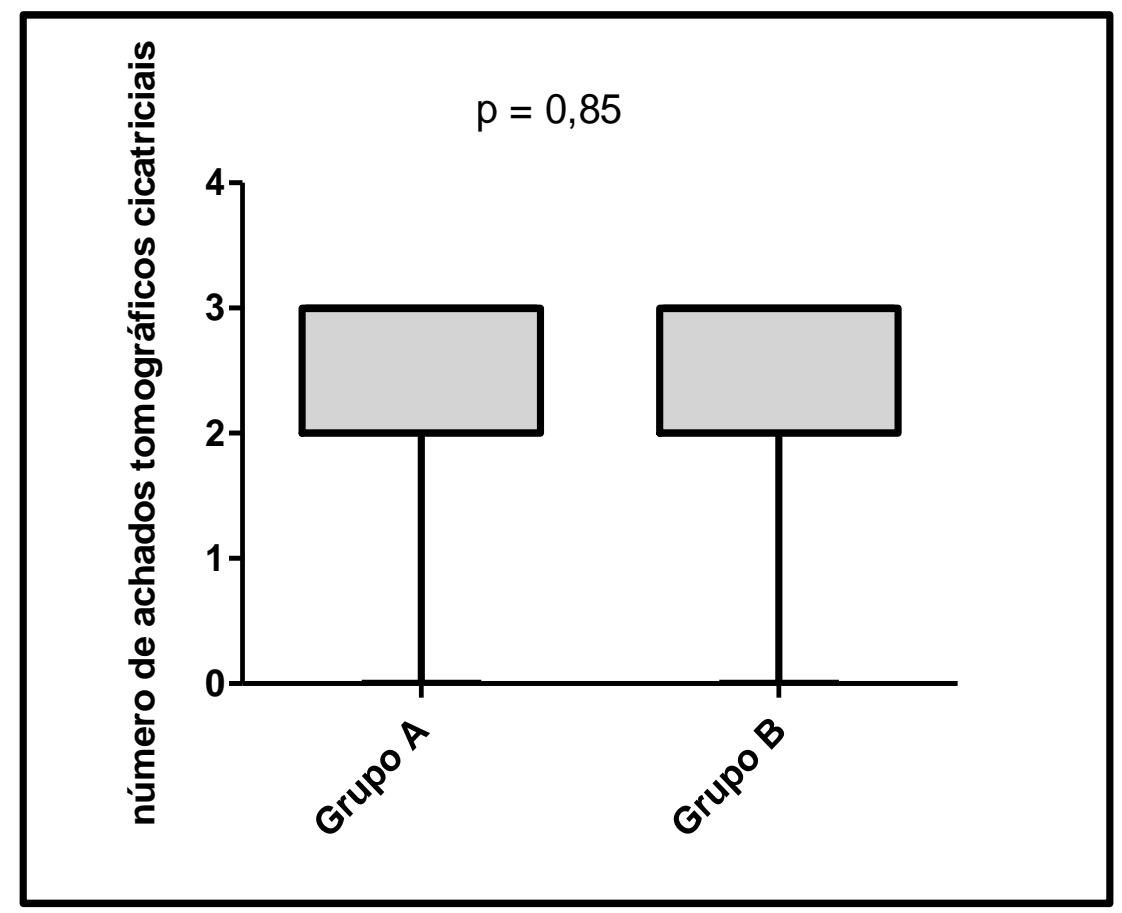

Figura 13 - Comparação entre o grau de enfisema nos grupos A e B

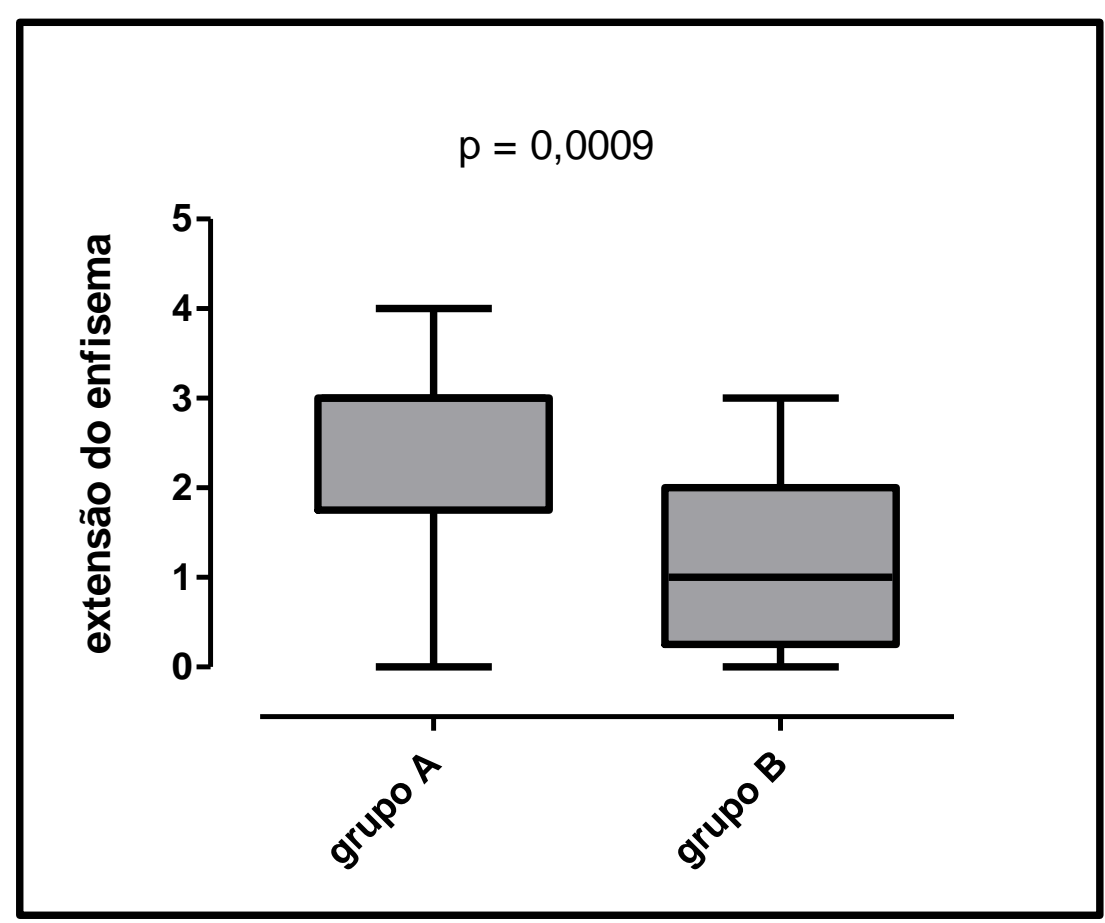


Quando os pacientes foram separados em dois grupos A e B, houve uma diferença estatisticamente significante em relação à $D L c o$ e $V V M$, mas sem diferença na CVF, VEF 1 , CPT ou VR (Tabela 13).

Tabela 13 - Resultados das comparações dos volumes, fluxos , capacidades pulmonares, difusão de $\mathrm{CO}$ e ventilação voluntária máxima nos dois grupos de pacientes

\begin{tabular}{|c|c|c|c|}
\hline & Grupo A & Grupo B & \\
\hline & $\%$ predito $\pm \mathrm{DP}$ & $\%$ predito $\pm \mathrm{DP}$ & $p$ \\
\hline CVF & $91,0 \pm 3,2$ & $97,0 \pm 1,8$ & 0,12 \\
\hline $\mathrm{VEF}_{1}$ & $72,1 \pm 3,9$ & $80,2 \pm 2,9$ & 0,10 \\
\hline CPT & $98,8 \pm 3,9$ & $101,3 \pm 1,9$ & 0,58 \\
\hline VR & $122,4 \pm 9,9$ & $120,6 \pm 5,6$ & 0,87 \\
\hline DLco & $49.2 \pm 3.8$ & $66.9 \pm 3.4$ & 0.001 \\
\hline VVM & $59,3 \pm 7,0$ & $76,5 \pm 3,9$ & 0,04 \\
\hline $\begin{array}{l}\text { Valores } \\
\text { ao final } \\
=\text { difusãc } \\
\text { máxima }\end{array}$ & $\begin{array}{l}\text { CVF = capacidad } \\
\text { capacidade pulm } \\
\mathrm{VR}=\text { volume resic }\end{array}$ & $\begin{array}{l}\text { tal forçada; } \mathrm{VEF}_{1}=\mathrm{vo} \\
\text { ir total; } \mathrm{VR}=\text { volume } \\
\mathrm{I} \mathrm{VVM}=\text { ventilação v }\end{array}$ & $\begin{array}{l}\text { e expirado } \\
\text { dual; DLco } \\
\text { ttária }\end{array}$ \\
\hline
\end{tabular}

No que tange à distância caminhada no TC6M, não houve diferença significante entre os dois grupos A e B na distância percorrida, conforme está mostrado na tabela 14. 
Tabela 14 - Comparação do teste de caminhada de seis minutos entre os dois grupos A e B

\begin{tabular}{lccc} 
& Grupo A & Grupo B & P \\
\hline Distância (m) & $482 \pm 15$ & $489 \pm 9$ & 0,71 \\
\hline
\end{tabular}

Valores distribuídos em media \pm DP. DP = desvio padrão

Em relação ao teste ergoespirométrico, não houve diferença significante entre $0 \mathrm{VO}_{2}$ máx nem na queda da capacidade inspiratória, mas houve diferença na reserva ventilatória, na $\mathrm{SpO}_{2}$ no pico do exercício e na relação $\mathrm{VE} / \mathrm{VCO}_{2}$ entre os grupos $\mathrm{A}$ e $\mathrm{B}$, conforme está mostrado na tabela 15.

Tabela 15 - Comparação das variáveis ventilatórias entre os dois grupos A e B

\begin{tabular}{|c|c|c|c|}
\hline & Grupo A & Grupo B & $\mathbf{P}$ \\
\hline $\mathrm{VO}_{2}$ máx (\% predito) & $79,5 \pm 3,9$ & $81,6 \pm 3,6$ & 0,70 \\
\hline $\begin{array}{l}\text { Diferença Cl inicial - final } \\
(\%)\end{array}$ & $8,0 \pm 1,1$ & $9,4 \pm 1,1$ & 0,39 \\
\hline 1-VE/VVM & $21,2 \pm 5,2$ & $39,4 \pm 4,3$ & 0,01 \\
\hline $\mathrm{SpO}_{2}$ (pico exercício) & $91,7 \pm 1,0$ & $94,7 \pm 0,4$ & 0,01 \\
\hline $\mathrm{VE} / \mathrm{VCO}_{2}$ & $38,3 \pm 1,5$ & $34,2 \pm 1,2$ & 0,04 \\
\hline
\end{tabular}

Valores distribuídos em media \pm DP. DP = desvio padrão 
No questionário de qualidade de vida relacionada a saúde (SGRQ), não houve diferença estatística entre a pontuação no grupo $A$ em relação ao grupo $B$, conforme mostrado na tabela 16. No índice de dispneia (MRC), também não houve uma diferenciação significativa entre os grupos (tabela 17).

Tabela 16 - Pontuação no Questionário do Hospital Saint George na

Doença Respiratória nos grupos A e B

\begin{tabular}{lccc}
\hline & GRUPO A & GRUPO B & p \\
TOTAL \pm DP & & \\
$\%$ total \pm DP & $15,71 \pm 3,13$ & $16,55 \pm 2,53$ & 0,83 \\
\hline \multicolumn{2}{l}{ Valores distribuídos em média \pm DP. DP = desvio padrão } &
\end{tabular}

Tabela 17 - Pontuação no Questionário do MRC nos grupos A e B

\begin{tabular}{cccc}
\hline & GRUPO A & GRUPO B & p \\
MRC (IQ) & $1(1-2)$ & $1(1-2)$ & 0,75 \\
\hline Valores distribuídos em mediana (IQ). IQ = interquartil &
\end{tabular}


5. DISCUSSÃO 
Nosso estudo é o primeiro a realizar uma avaliação completa, tanto do ponto de vista radiológico quanto funcional e do impacto na qualidade de vida relacionada à saúde em pacientes com PCM tratados, com critérios de inatividade de doença.

É o primeiro também a buscar características individuais que estejam ligadas a um maior acometimento da troca gasosa no exercício, medido pelo grau de dessaturação no teste de caminhada de seis minutos.

Assim como a tuberculose e a histoplasmose, a PCM é adquirida através da inalação de propágulos viáveis, que sofrem reativação no indivíduo adulto causando a forma crônica da doença, a qual tem no sistema respiratório seu principal sítio de atividade ${ }^{17,66}$. Nos tecidos infectados de indivíduos imunocompetentes, a imunidade inata do indivíduo induz reação inflamatória de padrão granulomatoso, na tentativa de restringir a proliferação e disseminação do fungo para outros órgãos do corpo ${ }^{42}$. Tuder e colaboradores descreveram, nos pulmões acometidos pelas lesões crônicas, além dos granulomas, fibrose densa e proliferação de fibras reticulínicas mesmo em áreas onde não se encontravam formações granulomatosas ${ }^{45}$. Os pulmões são, dessa forma, o principal local em que as lesões ativas e residuais da forma crônica aparecem regularmente, e é a remodelação fibrótica induzida pela resposta imune do hospedeiro que é considerada a causa das alterações em sua função respiratória, com potencial de incapacitar funcionalmente os indivíduos mesmo quando a micose é adequadamente tratada ${ }^{45,48}$.

Diferentemente do que já foi publicado sobre as alterações radiológicas pulmonares persistentes após 0 tratamento da Paracoccidioidomicose, o presente estudo encontrou uma incidência muito mais elevada de anormalidades nesse grupo de indivíduos, com $98 \%$ dos pacientes apresentando pelo menos uma alteração tomográfica. O uso da tomografia de tórax de alta resolução, método com sensibilidade muito maior para diagnóstico do acometimento pulmonar intersticial comparado à radiografia de tórax, pode explicar essa incidência tão elevada em comparação aos estudos anteriores ${ }^{65,66,68}$. Em nossa casuística, à TCAR, 
48 pacientes apresentaram distorção arquitetural, 44 reticulado ou espessamento do septo interlobular e 37 bandas parenquimatosas, possivelmente por causa da disseminação fúngica ao longo dos vasos linfáticos pulmonares com posterior estímulo fibrosante do microorganismo no parênquima do pulmão ${ }^{48,50,45}$. Marchiori e colaboradores, em estudo tomográfico-patológico, já mostraram que os achados de áreas de espessamento septal interlobular, distorção arquitetural, faveolamento e enfisema remetem anatomopatologicamente a áreas de fibrose do parênquima pulmonar ${ }^{68}$. $O$ achado de espessamento do interstício peribroncovascular em 31 pacientes, com predominância do padrão difuso (84\%) nos campos médios e superiores, também corrobora a teoria de Tuder e associados sobre a disseminação linfática da doença ${ }^{45,66}$. Por outro lado, diferentemente das descrições tomográficas de pacientes pré tratamento, nas quais evidencia-se frequentemente vidro fosco, consolidações, nódulos e cavitações ${ }^{65-67}$, em nosso estudo os achados de consolidação e cavitação foram bastante raros ( 4 e $2 \%$, respectivamente), confirmando a inatividade da doença em nossa coorte estudada. $O$ achado de vidro fosco, que esteve presente em $46 \%$ dos pacientes, pode ser explicado mais provavelmente pela presença de fibrose abaixo da sensibilidade da tomografia ${ }^{68,84}$, ao contrário de uma possível atividade inflamatória no septo alveolar ou exsudato alveolar celular, que estariam ligados mais à fase ativa da micose. Uma alteração interessante e não previamente descrita foi o achado de mosaico em 38 pacientes, denotando um acometimento de pequenas vias aéreas em uma porcentagem significativa dessa população. Esse dado, entretanto, deve ser analisado com cautela, haja vista a elevada incidência de exposição tabágica que poderia ser responsável pela presença da bronquiolite respiratória, doença intersticial tabaco-relacionada que tem como característica uma agressão de vias aéreas terminais e que poderia explicar tanto o mosaico como as áreas em vidro fosco.

Há, desse modo, que se levar em consideração os altos índices de exposição tabágica na população estudada, exposição extremamente prevalente em qualquer estudo relacionado à paracoccidioidomicose. Sabe- 
se que ela está presente em até $90 \%$ dos indivíduos acometidos por essa micose e é considerada, inclusive, relevante fator de risco para seu desenvolvimento ${ }^{17,33}$. Enfisema centrolobular ou parasseptal, presentes em $82 \%$ dos indivíduos estudados em nossa coorte, têm sua gênese presumível na exposição tabágica. É importante frisar, entretanto, que tais achados não foram, em nenhum dos pacientes, encontrados sem a associação a alguma outra alteração relacionada a um acometimento intersticial fibrosante possivelmente relacionado à resolução da infecção fúngica.

Assim como as alterações radiológicas, que se mostraram muito mais prevalentes que anteriormente descrito, as alterações funcionais foram bastante frequentes. Setenta por cento dos pacientes apresentaram distúrbio obstrutivo, valor um pouco mais elevado que estudos anteriores. Campos e colaboradores, estudando 58 pacientes, encontraram distúrbio obstrutivo em $55 \%{ }^{71}$, já o mesmo autor, em 1986, estudando 35 pacientes, descreve alterações obstrutivas em $57 \%$ dos indivíduos. Há que se frisar, entretanto, que $85 \%$ dos pacientes em nosso trabalho apresentaram um distúrbio ventilatório obstrutivo considerado leve $\left(\mathrm{VEF}_{1}>60 \%\right)$, e apenas um paciente apresentou $\mathrm{VEF}_{1}$ abaixo de $40 \%$, este com idade semelhante à media porém com carga tabágica bastante superior $(80 \mathrm{a} / \mathrm{m})$.

Em nossa avaliação, os pacientes apresentaram na média um distúrbio obstrutivo leve, com redução dos fluxos médios e redução leve da capacidade de difusão e na ventilação voluntária máxima medida (tabela 6). Não houve achado de hiperinsuflação pulmonar, mas pelo valor do VR ser $121 \%$ do predito a relação VR/CPT mostrou-se aumentada (VR/CPT $=0,38$ ), mostrando uma tendência ao aprisionamento aéreo, corroborando o achado do mosaico na tomografia de tórax. Não houve resposta ao uso de broncodilatador inalatório (Tabela 7).

$\mathrm{Na}$ literatura sobre as alterações da PCM em pacientes tratados, quando utilizada a gasometria arterial e o calculo do gradiente alvéoloarterial para diagnosticar distúrbio na troca gasosa, é descrita uma alteração na totalidade dos pacientes estudados ${ }^{71,72,75}$. Nos nossos pacientes, a DLco média foi $61 \%$, mostrando a presença de uma alteração na troca gasosa 
medida pela difusão do CO. Nove dos 50 pacientes tiveram redução acentuada na DLco (DLCO<40\%).

Uma possível explicação para os achados acima descritos pode ser a presença de alterações intersticiais fibróticas associadas ao enfisema pulmonar, assim como já foi recentemente descrito na fibrose pulmonar combinada ao enfisema (CPFE, do inglês Combined pulmonary fibrosis and emphysem) ${ }^{100}$ 101-103. Na CPFE, devido à presença de enfisema predominando nos lobos superiores associado a alterações intersticiais fibrosantes nos lobos inferiores, são encontradas alterações espirométricas próximas ao normal, porém o distúrbio difusional é muito grave com intensa hipoxemia ao exercício e é frequente a presença de hipertensão pulmonar, distúrbios relacionados à alta mortalidade nessa síndrome ${ }^{100,}{ }^{104}$. No caso dos pacientes com PCM inativa, diferente da CPFE, as alterações intersticiais foram encontradas de forma difusa nos campos pulmonares e em menor intensidade. A capacidade de difusão, assim como a saturação de $\mathrm{O}_{2}$ em repouso (e também no exercício, como mostrado a seguir) não se mostraram alterados de forma tão intensa como na fibrose associada ao enfisema. Porém o mecanismo fisiopatológico das alterações funcionais encontradas parece ter semelhanças entre as duas patologias, guardadas as proporções de magnitude das alterações nas duas doenças.

Além das avaliações funcionais em repouso, nosso estudo realizou testes funcionais dinâmicos nos pacientes com PCM crônica inativa, a fim de estudar o grau de intolerância ao exercício desses indivíduos. É sabido que a capacidade aeróbica $\left(\mathrm{VO}_{2}\right.$ máx) de um indivíduo nem sempre pode ser predita através de avaliações em repouso, como na medida da CVF, VEF $1 \mathrm{e}$ DLco ${ }^{105}$, e por isso lançamos mão do teste ergoespirométrico e do TC6M para avaliação do real acometimento da capacidade respiratória desse grupo de pacientes.

O TCPE está intimamente associado à deterioração da qualidade de vida e elevada morbi-mortalidade em uma faixa ampla de doenças cardiorrespiratórias, e tem a habilidade de avaliar tanto parâmetros ventilatórios quanto cardiovasculares. Nosso trabalho mostrou que, em 
média, a capacidade aeróbica medida através do TCPE nos pacientes com PCM inativa está mantida. $\mathrm{O}$ achado de uma média do consumo máximo de $\mathrm{O}_{2}$ de $81 \%$, com reserva ventilatória média de $40 \%$ e ausência de dessaturação no pico do exercício $\left(\mathrm{SpO}_{2}\right.$ média $\left.=94 \%\right)$, mostra boa capacidade aeróbica, sem limitação respiratória ao esforço, nesse grupo de pacientes. Ainda, a despeito do frequente achado de mosaico e da relação VR/CPT discretamente aumentada, a queda da capacidade inspiratória média de $9 \%$ aponta para ausência de hiperinsuflação dinâmica nesse grupo de pacientes, achado que também pode ser explicado pela presença de alterações intersticiais associadas às de vias aéreas, reduzindo a complacência pulmonar em associação ao aumento da resistência ao fluxo aéreo ${ }^{100,106}$. Tampouco houve sinais de limitação cardiovascular, com pulso de oxigênio médio de $103 \%$. E dos 50 pacientes avaliados, apenas um apresentou alteração eletrocardiográfica sugestiva de isquemia miocárdica, posteriormente afastada através de estudo angiográfico coronariano. Isso mostra que, em média, não há repercussão significante da capacidade aeróbica nesse grupo de pacientes com PCM inativa, apesar das alterações tomográficas cicatriciais bastante frequentes.

Além do TCPE, os 50 pacientes foram submetidos ao TC6M, com holter de oximetria. A eficácia do teste de caminhada de seis minutos para avaliar pneumopatias graves como fibrose pulmonar idiopática, hipertensão pulmonar, DPOC e CPFE tem comprovação tanto para avaliação prognóstica quanto de eficácia de tratamento ${ }^{81,91,101}$. Ele pode ser usado como critério de gravidade e indicação para transplante, indicação de uso de oxigenoterapia complementar, e tem boa correlação com a capacidade funcional e sobrevida dos pacientes com pneumopatias crônicas. Além disso, é uma ferramenta de baixo custo e de fácil aplicação sem a necessidade de utilização de aparelhos sofisticados ou medições elaboradas 107, 108 . Finalmente, alguns estudos mostram que o TC6M pode ser ainda mais sensível que o TCPE para avaliação de dessaturação ao exercício ${ }^{83}$. Por esses motivos, utilizamos esse critério para avaliação de um grupo de pacientes com doença pulmonar mais grave, utilizando assim a presença de 
dessaturação (queda $>4 \%$ em relação à $\mathrm{SpO}_{2}$ no repouso) no TC6M para divisão da coorte de indivíduos em dois grupos em relação a gravidade.

$\mathrm{Na}$ avaliação do TC6M, nossa coorte de pacientes mostrou valores normais para a distância caminhada (mediana de 131\% do esperado), mostrando um baixo impacto na das alterações pulmonares na PCM póstratamento na distância caminhada. Tampouco foi encontrada dessaturação ao final do exercício em na média do nosso grupo de pacientes. Isso pode ser explicado pelas alterações funcionais serem leves a ponto de não alterarem a distância caminhada, ou que os pacientes têm limitação leve o suficiente para permitir que a distância caminhada no teste não se altere em relação à população normal. Entretanto, ao se avaliar individualmente a dessaturação no TC6M, observou-se que 18 pacientes (36\% da amostra) apresentaram queda da $\mathrm{SpO}_{2}$ maior que $4 \%$ em relação ao repouso, mostrando um déficit na troca gasosa em situações de esforço e reforçando ao achados de estudos prévios nos quais os indivíduos com PCM tratada apresentam alteração no gradiente alvéolo-arterial de oxigênio. Foram esses pacientes, considerados mais graves, que foram comparados com o restante da população estudada.

Finalmente, do ponto de vista da qualidade de vida relacionada à saúde, os pacientes atingiram pontuação total de $16 \%$ no escore de Saint George, o que mostra alteração na qualidade de vida (valor maior que 10\%), porém não em grau acentuado ${ }^{97}$. Estudo avaliando o SGRQ na população geral mostrou que o valor médio obtido nesse questionário foi $8,4 \%$, e que o valor $16 \%$ dos nossos pacientes encontra-se no limite superior do percentil $80{ }^{109}$, não podendo assim ser considerado grave o impacto na qualidade de vida relacionada à saúde dos pacientes avaliados. Ao se fazer a distinção em três parâmetros (sintomas, atividade e impacto), verificou-se que os valores obtidos pelos nossos pacientes nos três domínios específicos encontram-se próximos ao percentil 60 da população geral. Isso mostra que, apesar de portadores de enfermidade de tratamento prolongado, e com grau leve de alterações funcionais pós tratamento, nossa coorte de pacientes não tem sua qualidade de vida relacionada à saúde profundamente alterada pela 
doença respiratória. Resultados semelhantes foram encontrados no questionário de dispneia, no qual o valor mediano de 1 corresponde a afirmação que o indivíduo "só sofre de falta de ar durante exercícios intensos", mostrando novamente um baixo impacto na sensação de dispneia nos indivíduos com PCM inativa.

Pelo que foi exposto até o momento, os resultados encontrados na média da população estudada mostraram um baixo impacto funcional e na qualidade de vida desses pacientes a despeito das frequentes alterações cicatriciais à TCAR. Entretanto, é importante apontar que houve um grupo de pacientes que obteve um pior desempenho na avaliação funcional realizada, especificamente no que tange à troca gasosa no exercício.

Esse grupo, que se diferenciou do restante da população por uma queda na $\mathrm{SpO}_{2}>4 \%$ no teste de caminhada, apresentou também uma diferença estatisticamente significante em relação à VVM e à DLco medidas, mostrando um impacto maior com respeito à capacidade ventilatória, em associação à pior troca gasosa (Tabela 13).

A sorologia inicial (CIE) também se mostrou útil na mensuração da gravidade dos pacientes, na medida em que teve correlação com a DLco e também com a qualidade de vida, porém não se relacionou com as alterações tomográficas, como poderia ser esperado. Os pacientes mais graves apresentaram títulos mais altos de CIE pré tratamento (média de duas diluições; $1: 128$ vs 1:32), dados que poderiam ser justificados pela sorologia ser uma mensuração indireta da intensidade da resposta imune inicial perante o fungo, o que resultaria em um impacto cicatricial mantido nos pacientes com resposta mais intensa na fase ativa da PCM ${ }^{38}$. Interessante ressaltar que não houve diferença estatística entre a idade, medicação utilizada, carga tabágica ou tempo de tratamento entre os dois grupos. Tampouco houve diferença entre os 27 pacientes que estavam recebendo medicação antifúngica de manutenção, visto que $40 \%$ estavam no grupo A e $60 \%$ no grupo $B(p=0,34)$. Importante explicar essa elevada taxa de indivíduos em uso de medicação: é prática comum os pacientes ambulatoriais do serviço de infectologia serem mantidos com baixas doses 
de antifúngico com objetivo de prevenir recidivas da forma crônica da $\mathrm{PCM}^{110}$, mesmo após os critérios de inatividade da doença terem sido atingidos.

Do ponto de vista radiológico, ao serem comparadas as prevalências das anormalidades tomográficas visualizadas nos dois grupos do estudo, não foi encontrada diferença estatística entre o número de achados tomográficos alterados entre eles. Ambos apresentaram número elevado de alterações à TCAR, média de oito no grupo $A$ e sete no grupo $B$. Porém, ao se avaliar separadamente o grau de enfisema, a quantificação através da tomografia mostrou que o grupo $A$ apresenta maior grau de enfisema em relação ao grupo $B$ (figura 13). Isso mostra que os indivíduos que tiveram uma dessaturação no TC6M maior que 4\% tiveram, em média, mais enfisema na tomografia que aqueles que não dessaturaram. Esses dados sugerem que a destruição parenquimatosa pelo enfisema tem papel mais preponderante que as alterações intersticiais cicatriciais, o que é corroborado pelo fato de ao se estudar essas alterações em separado não haver diferença significante entre os pacientes (figura 12).

Em relação ao TCPE, quando os pacientes foram separados nos dois grupos $\mathrm{A}$ e $\mathrm{B}$, não foi encontrado um $\mathrm{VO}_{2}$ máx mais baixo no grupo $\mathrm{A}$ (grupo $A: 79,5 \pm 3,9$ vs grupo $B: 81,6 \pm 3,6 ; p=0,70$ ). Entretanto houve diferença significante na reserva ventilatória entre os dois grupos $(\mathrm{p}=0,01)$, na $\mathrm{SpO}_{2}$ no pico do exercício $(p=0,01)$ e na $\mathrm{VE} / \mathrm{VCO}_{2}(p=0,04)$, mostrando um maior acometimento da ventilação/perfusão com pior desempenho do componente ventilatório no exercício, que porém não teve repercussão na capacidade final no exercício (tabela 15). Importante frisar que não foram encontrados sinais de sugestivos de hipertensão pulmonar na coorte de pacientes estudados, e que as variáveis que se mostraram mais alteradas no grupo $\mathrm{A}$ foram preponderantemente ventilatórias.

$\mathrm{Na}$ avaliação da diferença na distância percorrida no TC6M (tabela 10), também não houve diferença estatística entre os grupos estudados, indicando que apesar da disfunção mais grave da troca gasosa os pacientes atingem valores normais na distância no TC6M. A literatura trata da 
controvérsia sobre o uso da distância caminhada ou a dessaturação como parâmetro com melhor correlação com a função pulmonar e sobrevida nas doenças respiratórias ${ }^{82}$, e alguns autores chegam a preconizar o uso de um índice que inclua ambos os parâmetros avaliados nas doenças intersticiais ${ }^{82}$, 111. No nosso caso, a distância caminhada teve valores normais mostrando que esse índice tem baixa sensibilidade para avaliação do impacto funcional nesses doentes, talvez devido ao fato de muito serem ainda trabalhadores braçais e manterem atividade física diária intensa, com bom condicionamento muscular. A dessaturação ao esforço, por outro lado, foi capaz de mostrar que uma parcela dessa população, a despeito de percorrer distâncias nos limites da normalidade (e até acima deste), tem alteração na troca gasosa capaz de fazer com que a oxigenação periférica caia sensivelmente (mesmo que isso não impeça a realização da atividade física proposta).

Interessante o achado da comparação dos resultados da avaliação da qualidade de vida relacionada à saúde nos dois grupos estudados, no qual não foi vista maior pontuação no grupo com maior dessaturação ao esforço (tabelas 16 e 17). Isso corrobora a hipótese das alterações respiratórias nos pacientes estudados serem frequentes, porém sem gravidade suficiente para trazer um impacto muito grande na qualidade de vida relacionada à saúde. Mesmo no grupo considerado mais grave funcionalmente, a média da pontuação no SGRQ foi 16,5\%; e o grupo apresentou no MRC a média de 1 (dispneia aos exercícios intensos).

A explicação fisiopatológica do porquê de um grupo de pacientes apresentar sequelas pulmonares mais graves ainda está a ser determinada. É aceitável sugerir que alguns pacientes demorem mais para fazer o diagnostico e iniciar o tratamento, permitindo que o processo fibrosante esteja mais avançado e estabelecido quando o tratamento se principia ${ }^{47}$. Outra hipótese plausível seria a de existir diferenças na virulência entre linhagens distintas de diversas regiões do Brasil, ou entre diferentes quaseespécies de Paracoccidioides, como recentemente publicado ${ }^{10}$. Diferenças na relação hospedeiro-parasita com respostas e regulações imunes 
individuais distintas também poderiam justificar discrepâncias entre a progressão da doença e ulterior impacto respiratório ${ }^{38}$. Finalmente, características genéticas e fatores individuais que levassem aos indivíduos desenvolverem mais enfisema frente a uma carga tabágica semelhante podem ter levado um grupo de pacientes desenvolver essa alteração mais frequentemente que o restante da população.

Nosso estudo tem algumas limitações que precisam ser reconhecidas. A natureza monocêntrica do trabalho e o fato de que o centro estar localizado em uma região não endêmica para paracoccidioidomicose podem ser responsáveis por algum grau de viés de seleção, especialmente no que tange ao grau de acometimento dos pacientes, que tendem a ser graves em um centro quaternário. No entanto, nós acreditamos que por ser um dos maiores centros de referência para o tratamento no Brasil para patologias infecciosas e pulmonares, esse viés seja reduzido até um grau aceitável.

Outro ponto a ser levantado é que, como mostrado na figura 1, foram utilizadas diferentes classes de medicações antifúngicas, o que poderia funcionar como fator de confusão na análise dos resultados. Entretanto, ainda não há dados na literatura que comprovem uma superioridade entre uma medicação antifúngica sobre a outra, e muitos dos nossos pacientes foram tratados antes do Consenso Brasileiro indicar o Itraconazol como medicação de escolha ${ }^{28,76,78}$. Mais importante é frisar que todos os pacientes avaliados, independentemente do antimicrobiano utilizado, apresentaram critérios de doença inativa no momento de nossa avaliação, independente do tempo de tratamento ou classe de droga utilizada.

Outra limitação, essa inerente a estudos transversais, é a ausência de avaliação prévia dos pacientes, que foram estudados numa condição de inatividade da doença, mas sem dados de comparação com o status prétratamento. Tampouco foi possível obter a informação sobre o tempo entre o princípio dos sintomas e o início do tratamento. Esse dado é especialmente difícil de obter na Paracoccidioidomicose em sua forma crônica pelo início insidioso dos sintomas com difícil caracterização do princípio da doença 
ativa, além do fator de confusão do tabagismo como causador de tosse e expectoração, queixas iniciais da PCM.

Finalmente, o tabagismo é fator de confusão em qualquer estudo que implique em avaliação tomográfica e funcional respiratória. Na PCM, de maneira especial, existe a dificuldade de se encontrar um grupo controle não tabagista, pela relação de risco muito aumentado de doença nos pacientes tabagistas e pela altíssima prevalência de tabagistas em coortes de pacientes com Paracoccidioidomicose, em especial na sua forma crônica ${ }^{19}$, 23, 33. Dos nossos pacientes avaliados, a quase totalidade era formada por tabagistas, impossibilitando qualquer comparação entre os achados do único paciente não tabagista em relação os demais indivíduos.

Mesmo sob a luz destas limitações, nossos dados possuem consistência para permitir a conclusão sobre a apresentação clínica, tomográfica, funcional e da qualidade de vida dos pacientes com PCM inativa.

Esses dados buscam esclarecer alguns dos pontos ainda obscuros desta afecção tão prevalente e fascinante e de seu acometimento pulmonar e posterior impacto cicatricial. 
6. CONCLUSÃO 
Em conclusão, nosso estudo mostra que os pacientes com paracoccidioidomicose tratada, e com critérios de inatividade de doença, apresentam anormalidades residuais extremamente frequentes à tomografia de tórax. Apesar desses achados, a micose não leva a distúrbio respiratório grave ou incapacitante na maioria dos pacientes, tampouco há impacto grave na qualidade de vida relacionada à saúde na ampla maioria dos indivíduos.

Em uma parcela dessa população, entretanto, ocorre um maior comprometimento na troca gasosa no teste de caminhada que se relaciona clinicamente com sorologia inicial mais alta e maior grau de enfisema na tomografia de tórax pós-tratamento; porém sem relação com alterações mais graves nas provas funcionais realizadas, na capacidade aeróbica medida pelo TCPE ou maior impacto na qualidade de vida relacionada à saúde. 
7. REFERÊNCIAS BIBLIOGRÁFICAS 
1. Lutz A. Uma mycose pseudococcidica localisada na bocca e observada no Brazil. Contribuicao ao conhecimento das hyphoblastomycoses americanas. Bras-Med. 1908;(22):121-4.

2. de Almeida Soares CM, Mendes-Giannini MJ, Felipe MS, Chaturvedi V. A centennial: discovery of Paracoccidioides brasiliensis. Mycopathologia. 2008;165(4-5):179-81.

3. Londero AT. Paracoccidioidomicose: I. Patogenia, formas clínicas, manifestaçöes pulmonares e diagnóstico. J Pneumol. 1986;12(1):41-57.

4. Lacaz CS. Evolução dos conhecimentos sobre a paracoccidioidomicose. Um pouco de sua história. Del Negro G LC, Fiorillo AM, editor. Sao Paulo: Sarvier-Edusp; 1982.

5. Bethlem EP, Capone D, Maranhao B, Carvalho CR, Wanke B. Paracoccidioidomycosis. Curr Opin Pulm Med. 1999;5(5):319-25.

6. Moreira APV. Paracoccidioidomicose: histórico, etiologia, epidemiologia, patogênese, formas clínicas, diagnóstico laboratorial e antígenos. Sao Paulo; 2011 [updated 2011; cited 20/08/2011]; Disponível em: http://www.cve.saude.sp.gov.br/agencia/bepa51_paracocci.htm.

7. Franco M, Montenegro MR. Paracoccidioidomicose. In: Lopes E, Chapadeiro E, Tafuri W, editors. Bogliolo L Patologia 6 edição. Rio de Janeiro: Guanabara Koogan; 2000. p. 1239-49.

8. Colombo AL. Paracoccidioidomycosis: advances and unmet needs 100 years after its initial description by Lutz. J Venom Anim Toxins incl Trop Dis. 2008;14(3):387-92.

9. San-Blas G, Nino-Vega G. Paracoccidioides brasiliensis: chemical and molecular tools for research on cell walls, antifungals, diagnosis, taxonomy. Mycopathologia. 2008;165(4-5):183-95.

10. Matute DR, McEwen JG, Puccia R, Montes BA, San-Blas G, Bagagli E, et al. Cryptic speciation and recombination in the fungus Paracoccidioides brasiliensis as revealed by gene genealogies. Mol Biol Evol. 2006;23(1):65-73.

11. Teixeira MM, Theodoro RC, de Carvalho MJ, Fernandes L, Paes HC, Hahn RC, et al. Phylogenetic analysis reveals a high level of speciation in the Paracoccidioides genus. Mol Phylogenet Evol. 2009;52(2):273-83.

12. Borges-Walmsley $\mathrm{MI}$, Chen $\mathrm{D}$, Shu $\mathrm{X}$, Walmsley AR. The pathobiology of Paracoccidioides brasiliensis. Trends Microbiol. 2002;10(2):80-7.

13. Martinez R, Ferreira MS, Telles FQ, Medes RP, Borges AS, Giannini MJSM, et al. Paracoccidioidomicose. In: Focaccia R, editor. Veronesi-Focaccia : Tratado de Infectologia. 4 ed. Sao Paulo: Editora Atheneu; 2009. p. 1515-45.

14. Brummer E, Castaneda E, Restrepo A. Paracoccidioidomycosis: an update. Clin Microbiol Rev. 1993;6(2):89-117.

15. Franco M, Sano A, Kera K, Nishimura K, Takeo K, Miyaji M. Chlamydospore formation by Paracoccidioides brasiliensis mycelial form. Rev Inst Med Trop Sao Paulo. 1989;31(3):151-7.

16. Tercarioli GR, Bagagli E, Reis GM, Theodoro RC, Bosco Sde M, Macoris SA, et al. Ecological study of Paracoccidioides brasiliensis in soil: growth ability, conidia production and molecular detection. BMC Microbiol. 2007;7:92.

17. Restrepo A, Benard G, de Castro CC, Agudelo CA, Tobon AM. Pulmonary paracoccidioidomycosis. Semin Respir Crit Care Med. 2008;29(2):182-97.

18. Colombo AL, Tobon A, Restrepo A, Queiroz-Telles F, Nucci M. Epidemiology of endemic systemic fungal infections in Latin America. Med Mycol. 2011;49(8):785-98.

19. Coutinho ZF, Silva D, Lazéra $M$, Petri V, Oliveira RM, Sabroza PC, et al. Paracoccidioidomycosis mortality in Brazil (1980-1995). Cad Saúde Pública. 2002;18(5):1441-54. 
20. Blotta MH, Mamoni RL, Oliveira SJ, Nouer SA, Papaiordanou PM, Goveia A, et al. Endemic regions of paracoccidioidomycosis in Brazil: a clinical and epidemiologic study of 584 cases in the southeast region. Am J Trop Med Hyg. 1999;61(3):390-4.

21. Baldi BG, Costa AN, Carvalho CRR. Infecções pulmonares causadas por fungos. in: "Clínica Médica", volume 2 - doenças cardiovasculares, doenças respiratórias e emergências e terapia Intensiva. Barueri, SP: Editora Manole; 2009. p. 509-19.

22. Wanke B, Aide MA. Chapter 6--paracoccidioidomycosis. J Bras Pneumol. 2009;35(12):1245-9.

23. Bellissimo-Rodrigues F, Machado AA, Martinez R. Paracoccidioidomycosis epidemiological features of a 1,000-cases series from a hyperendemic area on the southeast of Brazil. Am J Trop Med Hyg. 2011;85(3):546-50.

24. Maluf ML, Pereira SR, Takahachi G, Svidzinski TI. [Prevalence of paracoccidioidomycosis infection determined by sorologic test in donors' blood in the Northwest of Parana, Brazil]. Rev Soc Bras Med Trop. 2003;36(1):11-6.

25. Martinez R. Paracoccidioidomycosis: the dimension of the problem of a neglected disease. Rev Soc Bras Med Trop. 2010;43(4):480.

26. Moreira APV. Paracoccidioidomicose: histórico, etiologia, epidemiologia, patogênese, formas clínicas, diagnóstico laboratorial e antígenos. Boletim Epidemiológico Paulista. 2008;5(51).

27. Prado M, Silva MBd, Laurenti R, Travassos LR, Taborda CP. Mortality due to systemic mycoses as a primary cause of death or in association with AIDS in Brazil: a review from 1996 to 2006. Mem Inst Oswaldo Cruz. 2009;104(3):513-21.

28. Shikanai-Yasuda MA, Telles Filho Fde Q, Mendes RP, Colombo AL, Moretti ML. [Guidelines in paracoccidioidomycosis]. Rev Soc Bras Med Trop. 2006;39(3):297-310.

29. Shankar J, Restrepo A, Clemons KV, Stevens DA. Hormones and the resistance of women to paracoccidioidomycosis. Clin Microbiol Rev. 2011;24(2):296-313.

30. Salazar ME, Restrepo A, Stevens DA. Inhibition by estrogens of conidium-to-yeast conversion in the fungus Paracoccidioides brasiliensis. Infect Immun. 1988;56(3):711-3.

31. Pato AM, Giusiano G, Mangiaterra M. [Association of paracoccidioidomycosis with different pulmonary pathologies in a hospital in Corrientes Province, Argentina]. Rev Argent Microbiol. 2007;39(3):161-5.

32. Shikanai-Yasuda MA, Conceicao YM, Kono A, Rivitti E, Campos AF, Campos SV. Neoplasia and paracoccidioidomycosis. Mycopathologia. 2008;165(4-5):303-12.

33. Santos WA, Silva BM, Passos ED, Zandonade E, Falqueto A. Associação entre tabagismo e paracoccidioidomicose: um estudo de caso-controle no Estado do Espírito Santo, Brasil. Cad Saúde Pública. 2003;19(1):245-53.

34. Bagagli E, Theodoro RC, Bosco SM, McEwen JG. Paracoccidioides brasiliensis: phylogenetic and ecological aspects. Mycopathologia. 2008;165(4-5):197-207.

35. Stappaerts I, Bogers J, Ebo D, Vanden Broecke E, Stevens WJ, Van Marck E, et al. cANCA positivity in a Belgian patient with pulmonary paracoccidioidomycosis. Eur Respir J. 1997;10(10):2419-22.

36. Borelli D. Prevalence of systemic mycoses in Latin America. Pan American Health Organization Proc Int Symp Mycoses. 1970;205:28-38.

37. Bagagli E, Sano A, Coelho KI, Alquati S, Miyaji M, de Camargo ZP, et al. Isolation of Paracoccidioides brasiliensis from armadillos (Dasypus noveminctus) captured in an endemic area of paracoccidioidomycosis. Am J Trop Med Hyg. 1998;58(4):505-12.

38. Benard G. An overview of the immunopathology of human paracoccidioidomycosis. Mycopathologia. 2008;165(4-5):209-21. 
39. Alquati $\mathrm{SAB}$. Paracoccidioides brasiliensis não ocorre na forma endofítica em gramíneas da região de Botucatu-SP-Brasil [Mestrado]. Botucatu Faculdade de Medicina de Botucatu; 1999.

40. Kurita N, Oarada M, Miyaji M, Ito E. Effect of cytokines on antifungal activity of human polymorphonuclear leucocytes against yeast cells of Paracoccidioides brasiliensis. Med Mycol. 2000;38(2):177-82.

41. Taborda CP, Camargo ZP. Diagnosis of paracoccidioidomycosis by dot immunobinding assay for antibody detection using the purified and specific antigen gp43. J Clin Microbiol. 1994;32(2):554-6.

42. Calich VL, Vaz CA, Burger E. Immunity to Paracoccidioides brasiliensis infection. Res Immunol. 1998;149(4-5):407-17; discussion 99-500.

43. San-Blas G, San-Blas F. Paracoccidioides brasiliensis: cell wall structure and virulence. A review. Mycopathologia. 1977;62(2):77-86.

44. Franco M. Host-parasite relationships in paracoccidioidomycosis. J Med Vet Mycol. 1987;25(1):5-18.

45. Tuder RM, el Ibrahim R, Godoy CE, De Brito T. Pathology of the human pulmonary paracoccidioidomycosis. Mycopathologia. 1985;92(3):179-88.

46. Shikanai-Yasuda MA, Pereira PM, Yamashiro-Kanashiro E, Duarte MI, Assis CM, Geraldes EA, et al. Lung tissue mechanics in the early stages of induced paracoccidioidomycosis in rats. Braz J Med Biol Res. 1997;30(10):1175-9.

47. Cock AM, Cano LE, Velez D, Aristizabal BH, Trujillo J, Restrepo A. Fibrotic sequelae in pulmonary paracoccidioidomycosis: histopathological aspects in $B A L B / c$ mice infected with viable and non-viable paracoccidioides brasiliensis propagules. Rev Inst Med Trop Sao Paulo. 2000;42(2):59-66.

48. Restrepo S, Tobon A, Trujillo J, Restrepo A. Development of pulmonary fibrosis in mice during infection with Paracoccidioides brasiliensis conidia. J Med Vet Mycol. 1992;30(3):173-84.

49. Naranjo TW, Lopera DE, Diaz-Granados LR, Duque JJ, Restrepo AM, Cano LE. Combined itraconazole-pentoxifylline treatment promptly reduces lung fibrosis induced by chronic pulmonary paracoccidioidomycosis in mice. Pulm Pharmacol Ther. 2010;24(1):8191.

50. Franco L, Najvar L, Gomez BL, Restrepo S, Graybill JR, Restrepo A. Experimental pulmonary fibrosis induced by Paracoccidioides brasiliensis conidia: measurement of local host responses. Am J Trop Med Hyg. 1998;58(4):424-30.

51. Carvalho CRR, Kairalla RA, Filho RSC, Saldiva PHN, Filho JVB, Romeiro-Neto MM. O lavado broncoalveolar nas pneumopatias intersticiais pulmonares. Rev Hosp Clin Fac Med S Paulo. 1987;42(3):110-4.

52. Fornazim MC, Balthazar A, Quagliato R, Jr., Mamoni RL, Garcia C, Blotta MH. Evaluation of bronchoalveolar cells in pulmonary paracoccidioidomycosis. Eur Respir J. 2003;22(6):895-9.

53. de Camargo ZP. Serology of paracoccidioidomycosis. Mycopathologia. 2008;165(45):289-302.

54. Benard G, Kavakama J, Mendes-Giannini MJ, Kono A, Duarte AJ, Shikanai-Yasuda MA. Contribution to the natural history of paracoccidioidomycosis: identification of the primary pulmonary infection in the severe acute form of the disease--a case report. Clin Infect Dis. 2005;40(1):e1-4.

55. Fava SdC, Netto CF. Epidemiologic surveys of histoplasmin and paracoccidioidin sensitivity in Brazil. Rev Inst Med Trop Sao Paulo. 1998;40(3):155-64. 
56. Pereira RM, Bucaretchi F, Barison Ede M, Hessel G, Tresoldi AT. Paracoccidioidomycosis in children: clinical presentation, follow-up and outcome. Rev Inst Med Trop Sao Paulo. 2004;46(3):127-31.

57. Restrepo A, Trujillo M, Gomez I. Inapparent lung involvement in patients with the subacute juvenile type of paracoccidioidomycosis. Rev Inst Med Trop Sao Paulo. 1989;31(1):18-22.

58. Yamaga LY, Benard G, Hironaka FH, Castro LG, Funari MG, de Castro CC, et al. The role of gallium-67 scan in defining the extent of disease in an endemic deep mycosis, paracoccidioidomycosis: a predominantly multifocal disease. Eur J Nucl Med Mol Imaging. 2003;30(6):888-94.

59. Benard G, Costa AN, Ravanini J, Goulart S, Nicodemo EL, Barbas CS, et al. Fatal acute respiratory distress syndrome in a patient with paracoccidioidomycosis: first case report. Med Mycol. 2010;48(3):542-5.

60. Gomes E, Wingeter MA, Svidzinski TI. [Clinical-radiological dissociation in lung manifestations of paracoccidioidomycosis]. Rev Soc Bras Med Trop. 2008;41(5):454-8.

61. Paniago AM, Aguiar JI, Aguiar ES, da Cunha RV, Pereira GR, Londero AT, et al. [Paracoccidioidomycosis: a clinical and epidemiological study of 422 cases observed in Mato Grosso do Sul]. Rev Soc Bras Med Trop. 2003;36(4):455-9.

62. Valle AFd, Guimaraes RR, Lopes DJ, Capone D. Aspectos radiológicos torácicos na paracoccidioidomicose. Rev Inst Med Trop Sao Paulo. 1992;34(2):107-15.

63. Moraes CSd, Queiroz-Telles F, Marchiori E, Escuissato DL. Análise das alterações radiográficas pulmonares durante a terapêutica da paracoccidioidomicose. Radiol Bras. 2011;44(11):20-8.

64. Trad HS, Trad CS, Junior JE, Muglia VF. Revisão radiológica de 173 casos consecutivos de paracoccidioidomicose. Radiol Bras. 2006;39(3):175-9.

65. Barreto MM, Marchiori E, Amorim VB, Zanetti G, Takayassu TC, Escuissato DL, et al. Thoracic Paracoccidioidomycosis: Radiographic and CT Findings. Radiographics. 2012;32(1):71-84.

66. Funari M, Kavakama J, Shikanai-Yasuda MA, Castro LG, Bernard G, Rocha MS, et al. Chronic pulmonary paracoccidioidomycosis (South American blastomycosis): highresolution CT findings in 41 patients. AJR Am J Roentgenol. 1999;173(1):59-64.

67. Souza AS, Jr., Gasparetto EL, Davaus T, Escuissato DL, Marchiori E. High-resolution CT findings of 77 patients with untreated pulmonary paracoccidioidomycosis. AJR Am J Roentgenol. 2006;187(5):1248-52.

68. Marchiori E, Valiante PM, Mano CM, Zanetti G, Escuissato DL, Souza AS, Jr., et al. Paracoccidioidomycosis: high-resolution computed tomography-pathologic correlation. Eur J Radiol. 2009;77(1):80-4.

69. Tobon AM, Agudelo CA, Osorio ML, Alvarez DL, Arango M, Cano LE, et al. Residual pulmonary abnormalities in adult patients with chronic paracoccidioidomycosis: prolonged follow-up after itraconazole therapy. Clin Infect Dis. 2003;37(7):898-904.

70. Afonso JE, Nery LE, Romaldini H, Bogossian M, Ribeiro-Ratto O. [Pulmonary function in paracoccidioidomycosis (South American blastomycosis)]. Rev Inst Med Trop Sao Paulo. 1979;21(6):269-80.

71. Campos EP, Cataneo AMJ. Função pulmonar na evolução de 35 pacientes com paracoccidioidomicose. Rev Inst Med Trop Sao Paulo. 1986;28(5):330-6.

72. Campos EP, Padovani CR, Cataneo AMJ. Paracoccidioidomicose: estudo radiológico e pulmonar de 58 casos. Rev Inst Med Trop Sao Paulo. 1991;33(4):267-76.

73. Lemle A, Vieira LO, Milward GA, Miranda JL. Lung function studies in pulmonary South American blastomycosis. Correlation with clinical and roentgenologic findings. Am J Med. 1970;48(4):434-42. 
74. Lemle A, Wanke B, Mandel MB. Pulmonary localization of paracoccidioidomycosis: lung function studies before and after treatment. Rev Inst Med Trop Sao Paulo. 1983;25(12):73-8.

75. Lemle A, Wanke B, Miranda JL, Kropf GL, Mandel MB, Mandel S. Pulmonary function in paracoccidioidomycosis (South American blastomycosis). An analysis of the obstructive defect. Chest. 1983;83(5):827-8.

76. Shikanai-Yasuda MA, Benard G, Higaki Y, Del Negro GM, Hoo S, Vaccari EH, et al. Randomized trial with itraconazole, ketoconazole and sulfadiazine in paracoccidioidomycosis. Med Mycol. 2002;40(4):411-7.

77. Queiroz-Telles F, Goldani LZ, Schlamm HT, Goodrich JM, Espinel-Ingroff A, ShikanaiYasuda MA. An open-label comparative pilot study of oral voriconazole and itraconazole for long-term treatment of paracoccidioidomycosis. Clin Infect Dis. 2007;45(11):1462-9.

78. Menezes VM, Soares BG, Fontes CJ. Drugs for treating paracoccidioidomycosis. Cochrane Database Syst Rev. 2006;(2):CD004967.

79. Franco M, Montenegro MR, Mendes RP, Marques SA, Dillon NL, Mota NG. Paracoccidioidomycosis: a recently proposed classification of its clinical forms. Rev Soc Bras Med Trop. 1987;20(2):129-32.

80. Arango $M$, Yarzabal L. T-cell dysfunction and hyperimmunoglobulinemia $E$ in paracoccidioidomycosis. Mycopathologia. 1982;79(2):115-23.

81. ATS statement: guidelines for the six-minute walk test. Am J Respir Crit Care Med. 2002;166(1):111-7.

82. Pimenta SP, Rocha RB, Baldi BG, Kawassaki Ade M, Kairalla RA, Carvalho CR. Desaturation - distance ratio: a new concept for a functional assessment of interstitial lung diseases. Clinics (Sao Paulo). 2010;65(9):841-6.

83. Poulain M, Durand F, Palomba B, Ceugniet F, Desplan J, Varray A, et al. 6-minute walk testing is more sensitive than maximal incremental cycle testing for detecting oxygen desaturation in patients with COPD. Chest. 2003;123(5):1401-7.

84. Silva $\mathrm{Cl}$, Marchiori E, Souza Junior AS, Muller NL. Illustrated Brazilian consensus of terms and fundamental patterns in chest CT scans. J Bras Pneumol. 2010;36(1):99-123.

85. Boren HG. Alveolar fenestrae. Relationship to the pathology and pathogenesis of pulmonary emphysema. Am Rev Respir Dis. 1962;85:328-44.

86. Thurlbeck WM, Muller NL. Emphysema: definition, imaging, and quantification. AJR Am J Roentgenol. 1994;163(5):1017-25.

87. Diretrizes para Testes de Função Pulmonar. J Bras Pneumol. 2002;28, Supl 3.

88. Pereira CA, Sato T, Rodrigues SC. New reference values for forced spirometry in white adults in Brazil. J Bras Pneumol. 2007;33(4):397-406.

89. Neder JA, Andreoni S, Castelo-Filho A, Nery LE. Reference values for lung function tests. I. Static volumes. Braz J Med Biol Res. 1999;32(6):703-17.

90. Neder JA, Andreoni S, Peres C, Nery LE. Reference values for lung function tests. III. Carbon monoxide diffusing capacity (transfer factor). Braz J Med Biol Res. 1999;32(6):72937.

91. Soares MR, Pereira CA. Six-minute walk test: reference values for healthy adults in Brazil. J Bras Pneumol. 2011;37(5):576-83.

92. Borg GA. Psychophysical bases of perceived exertion. Med Sci Sports Exerc. 1982;14(5):377-81.

93. Neder JA, Nery LE, Castelo A, Andreoni S, Lerario MC, Sachs A, et al. Prediction of metabolic and cardiopulmonary responses to maximum cycle ergometry: a randomised study. Eur Respir J. 1999;14(6):1304-13.

94. Neder JA, Nery LE. Teste de Exercício Cardiopulmonar. J Bras Pneumol. 2002;28(Supl 3 - outubro):S166-S206. 
95. II Consenso Brasileiro sobre DPOC. Caracterização da doença pulmonar obstrutiva crônica - definição, epidemiologia, diagnóstico e estadiamento. J Bras Pneumol. 2004;30(5):S1-S5.

96. Bestall JC, Paul EA, Garrod R, Garnham R, Jones PW, Wedzicha JA. Usefulness of the Medical Research Council (MRC) dyspnoea scale as a measure of disability in patients with chronic obstructive pulmonary disease. Thorax. 1999;54(7):581-6.

97. Kovelis D, Segretti NO, Probst VS, Lareau SC, Brunetto AF, Pitta F. Validation of the Modified Pulmonary Functional Status and Dyspnea Questionnaire and the Medical Research Council scale for use in Brazilian patients with chronic obstructive pulmonary disease. J Bras Pneumol. 2008;34(12):1008-18.

98. Jones PW, Quirk FH, Baveystock CM, Littlejohns P. A self-complete measure of health status for chronic airflow limitation. The St. George's Respiratory Questionnaire. Am Rev Respir Dis. 1992;145(6):1321-7.

99. Sousa TC, Jardim JRB, Jones PW. Validação do Questionário do Hospital Saint George na Doença Respiratória (SGRQ) em pacientes portadores de doença pulmonar obstrutiva crônica no Brasil. J Bras Pneumol. 2000;16:119-25.

100. Jankowich MD, Rounds SI. Combined pulmonary fibrosis and emphysema syndrome: a review. Chest. 2012;141(1):222-31.

101. Cottin V, Cordier JF. The syndrome of combined pulmonary fibrosis and emphysema. Chest. 2009;136(1):1-2.

102. Cottin V, Nunes H, Brillet PY, Delaval P, Devouassoux G, Tillie-Leblond I, et al. Combined pulmonary fibrosis and emphysema: a distinct underrecognised entity. Eur Respir J. 2005;26(4):586-93.

103. Brillet PY, Cottin V, Letoumelin P, Landino F, Brauner MW, Valeyre D, et al. [Combined apical emphysema and basal fibrosis syndrome (emphysema/fibrosis syndrome): CT imaging features and pulmonary function tests]. J Radiol. 2009;90(1 Pt 1):4351.

104. Mejia M, Carrillo G, Rojas-Serrano J, Estrada A, Suarez T, Alonso D, et al. Idiopathic pulmonary fibrosis and emphysema: decreased survival associated with severe pulmonary arterial hypertension. Chest. 2009;136(1):10-5.

105. Palange P, Ward SA, Carlsen KH, Casaburi R, Gallagher CG, Gosselink R, et al. Recommendations on the use of exercise testing in clinical practice. Eur Respir $\mathrm{J}$. 2007;29(1):185-209.

106. Marciniuk DD, Sridhar G, Clemens RE, Zintel TA, Gallagher CG. Lung volumes and expiratory flow limitation during exercise in interstitial lung disease. J Appl Physiol. 1994;77(2):963-73.

107. Flaherty KR, Andrei AC, Murray S, Fraley C, Colby TV, Travis WD, et al. Idiopathic pulmonary fibrosis: prognostic value of changes in physiology and six-minute-walk test. Am J Respir Crit Care Med. 2006;174(7):803-9.

108. Marin JM, Carrizo SJ, Gascon M, Sanchez A, Gallego B, Celli BR. Inspiratory capacity, dynamic hyperinflation, breathlessness, and exercise performance during the 6-minutewalk test in chronic obstructive pulmonary disease. Am J Respir Crit Care Med. 2001;163(6):1395-9.

109. Ferrer M, Villasante C, Alonso J, Sobradillo V, Gabriel R, Vilagut G, et al. Interpretation of quality of life scores from the St George's Respiratory Questionnaire. Eur Respir J. 2002;19(3):405-13.

110. Yasuda MA. Pharmacological management of paracoccidioidomycosis. Expert Opin Pharmacother. 2005;6(3):385-97. 
111. Lettieri CJ, Nathan SD, Browning RF, Barnett SD, Ahmad S, Shorr AF. The distancesaturation product predicts mortality in idiopathic pulmonary fibrosis. Respir Med. 2006;100(10):1734-41. 
8. APÊNDICES 


\section{APÊNDICE 1 - Tabela de descritores da tomografia computadorizada de alta resolução do tórax}

\begin{tabular}{|c|c|}
\hline Achado tomográfico & Nome do paciente \\
\hline ESPESSAMENTO SEPTAL / RETICULADO & \\
\hline ESPESSAMENTO intersticio PERIBRONCOVASCULAR & \\
\hline BANDA parenquimatosa & \\
\hline opacidades RETRÁTEIS / DISTORÇÃO da arquitetura & \\
\hline CONSOLIDAÇÃO alveolar & \\
\hline opacidade em VIDRO FOSCO & \\
\hline ENFISEMA centrolobular e/ou para septal (++++) & \\
\hline ENFISEMA paracicatricial (++++) & \\
\hline ESPESSAMENTO BRONQUICO & \\
\hline BRONQUIECTASIAS e bronquiolectasias de tração & \\
\hline APRISIONAMENTO aereo & \\
\hline NÓDULO (até $3 \mathrm{~cm}$ ) & \\
\hline MICRONÓDULOS $(<0,3 \mathrm{~cm})$ & \\
\hline CAVITAÇÃO & \\
\hline ÁRVORE BROTAMENTO & \\
\hline LINFONODOMEGALIA & \\
\hline alteração PLEURAL & \\
\hline outros & \\
\hline localização / zonas & \\
\hline CENTRAL & \\
\hline PERIFERICA & \\
\hline CENTRAL + PERIFÉRICA & \\
\hline SUPERIOR (acima carina) & \\
\hline MÉDIO (carina - veias pulmonares ineriores) & \\
\hline INFERIOR (abaixo v. pulmonares) & \\
\hline DIFUSO (combinação de zonas) & \\
\hline
\end{tabular}


APÊNDICE 2 - Escala de Borg modificada

\begin{tabular}{|c|c|}
\hline 0 & Nenhuma \\
\hline 0,5 & Muito, muito leve \\
\hline 1 & Muito leve \\
\hline 2 & Leve \\
\hline 3 & Moderada \\
\hline 4 & Pouco intensa \\
\hline 5 & Intensa \\
\hline 6 & \\
\hline 7 & Muito intensa \\
\hline 8 & \\
\hline 9 & Muito, muito intensa \\
\hline 10 & Máxima \\
\hline
\end{tabular}


APÊNDICE 3 - Escala de MRC modificada

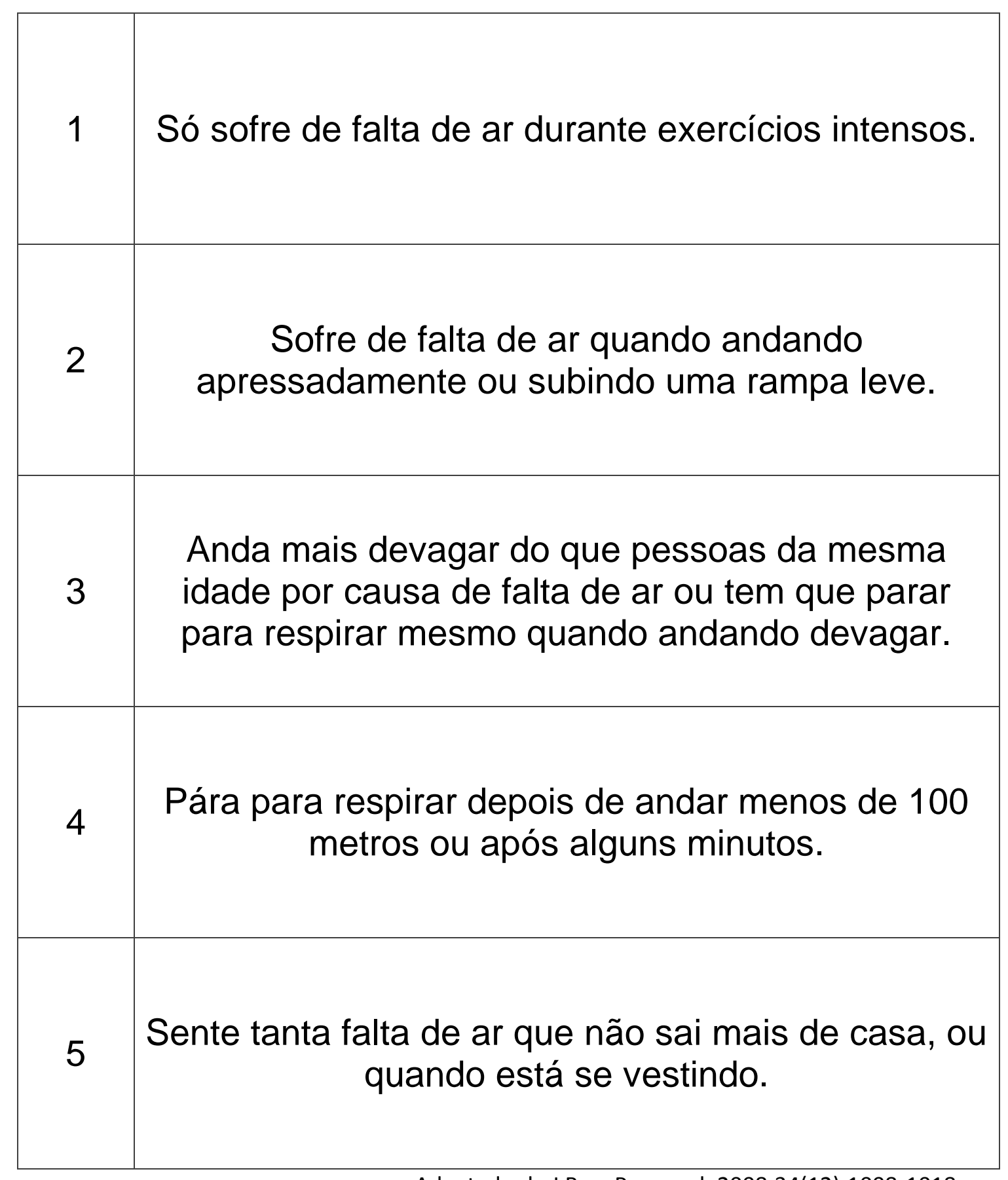

Adaptado de J Bras Pneumol. 2008;34(12):1008-1018 